\title{
Repairing the Damage: The Effect of Price Knowledge and Gender on Auto Repair Price Quotes
}

\section{Citation}

Busse, Meghan R., Ayelet Israeli, and Florian Zettelmeyer. 2017. "Repairing the Damage: The Effect of Price Knowledge and Gender on Auto Repair Price Quotes." Journal of Marketing Research 54 (1) (February): 75-95. doi:10.1509/jmr.13.0291.

\section{Published Version}

doi:10.1509/jmr.13.0291

\section{Permanent link}

http://nrs.harvard.edu/urn-3:HUL.InstRepos:34406568

\section{Terms of Use}

This article was downloaded from Harvard University's DASH repository, and is made available under the terms and conditions applicable to Other Posted Material, as set forth at http:// nrs.harvard.edu/urn-3:HUL.InstRepos:dash.current.terms-of-use\#LAA

\section{Share Your Story}

The Harvard community has made this article openly available.

Please share how this access benefits you. Submit a story.

\section{Accessibility}




\title{
Repairing the Damage: The Effect of Price Knowledge and Gender on Auto-Repair Price Quotes*
}

\author{
Meghan R. Busse \\ Northwestern University and NBER \\ Ayelet Israeli \\ Harvard University \\ Florian Zettelmeyer \\ Northwestern University and NBER
}

January 2016

${ }^{*}$ We wish to thank Brian Hafer, Georgette Ong, Tracey Virtue, and Melanie Webber for enabling us to run the experiments in this paper. This research was conducted in collaboration with AutoMD, whose call center employees conducted the primary data collection. The authors received no compensation from AutoMD for conducting this research. We are also grateful for the generous advice and help from Angela Lee and Eric Anderson. We thank Steve Tadelis, Jeroen Swinkels and seminar participants at Northwestern, Stanford, Yale, and the NBER IO Winter Meetings for many helpful comments and suggestions. We are grateful for helpful comments from three anonymous referees, as well as the editors. E-mail addresses for correspondence: m-busse@kellogg.northwestern.edu, aisraeli@hbs.edu, f-zettelmeyer@kellogg.northwestern.edu 


\title{
Repairing the Damage: \\ The Effect of Price Knowledge and Gender \\ on Auto-Repair Price Quotes
}

\begin{abstract}
In this paper we investigate whether sellers treat consumers differently on the basis of how well informed consumers appear to be. We implement a large-scale field experiment in which callers request price quotes from automotive repair shops. We show that sellers alter their initial price quotes depending on whether consumers appear to be correctly informed, uninformed, or misinformed about market prices. We find that repair shops quote higher prices to callers who cite a higher benchmark price. We find that women are quoted higher prices than men when callers signal that they are uninformed about market prices. However, gender differences disappear when callers mention a benchmark price for the repair. Finally, we find that repair shops are more likely to offer a price concession if asked to do so by a woman than a man.
\end{abstract}




\section{Introduction}

In a market in which prices are dispersed, consumers who have a good estimate of typical or average prices for an item or service may be better able to obtain low prices (or at least avoid paying high ones) than consumers who do not. This is because customers with good price knowledge are unlikely to accept a high price relative to the market average, knowing that only a little extra search effort is likely to yield a better price offer. Consumers typically have good price knowledge for "signpost" items they buy regularly (for example, regular gasoline or laundering of men's shirts). ${ }^{1}$ However, consumers are less likely to have good price knowledge about products they buy rarely.

Because of this, many people shop around for big-ticket items or services that they buy infrequently and for which overpaying can have a high dollar cost. The effectiveness of shopping around is blunted, however, if sellers treat buyers differently on the basis of how well informed a buyer appears to be about the product itself or about its price. Consumer education materials published by the Federal Trade Commission, an agency whose mandate is partly consumer protection, suggests that this may be a concern in some industries. The FTC publishes guides for consumers shopping for mortgages, cars and car repair, jewelry, products with extended warranties, antiques, funerals, mattresses, and a variety of other complicated, expensive, and/or infrequently purchased products. $^{2}$ These are the sorts of products and services that inspire in consumers a nagging suspicion that sellers will take advantage of them if they are not well-informed.

There are extensive theoretical and empirical literatures that have investigated price dispersion and the value of shopping around. ${ }^{3}$ The theoretical literature generally assumes that the price a firm offers a buyer doesn't depend on the buyer's characteristics; in most models, there are highpriced shops and low-priced shops, but a given shop will quote the same price to all buyers. In this paper, we investigate whether sellers treat consumers differently on the basis of how well informed consumers appear to be. We do so by using a field experiment in a setting in which sellers have some discretion about what price to offer an individual customer. Our experiment employs mystery shoppers who ask automobile repair shops for price quotes using scripts that reveal different degrees of price knowledge. The purpose of our experimental design is to illuminate a single aspect of the effect of customer information on prices; namely, how much sellers differentiate their initial price offers to customers on the basis of how informed customers appear to be. By using scripts to keep buyer behavior fixed, our experiment isolates sellers' responses to differences in buyer information.

\footnotetext{
${ }^{1}$ See Anderson and Simester (2008) for a review.

${ }^{2}$ See http://www.consumer.ftc.gov/topics/shopping-saving.

${ }^{3}$ See Baye, Morgan, and Scholten (2006) for a review of both the theoretical and empirical literatures. Notable empirical papers include Brown and Goolsbee (2002) and Sorensen (2000). Notable papers in the theoretical literature include Stigler (1961), Salop (1977), Salop and Stiglitz (1977), Carlson and McAfee (1983), Stahl (1989), Stahl (1996), and Anderson and de Palma (2005).
} 
The aim of the research design is explicitly not to capture the effect of consumer information on equilibrium transaction prices. Instead, it is to estimate one component of the overall effect: the seller response.

We perform two experiments. In our first and main experiment we test the effect of mentioning a benchmark price on seller responses by comparing price quotes obtained by callers who disavow any price knowledge (the "uninformed" condition) to those obtained by callers who mention that they have learned that the requested repair should cost $\$ 365$ (the "informed" condition, since $\$ 365$ is the approximate market average for the requested repair) or $\$ 510$ (the "misinformed" condition, since $\$ 510$ clearly exceeds the market average price for the requested repair). Since demographic differences have been known to affect outcomes in price negotiations, we vary the gender of callers. We anticipate that firms may assign different priors to the price knowledge of male and female callers.

We find that price knowledge affects repair shops' price quotes. When callers communicate that they are uninformed about the market price, the price quote is, on average, no different from when they communicate accurate information about the average market price. However, repair shops quote significantly higher prices to callers who are misinformed about prices than to those who are either uninformed or correctly informed.

Female callers are quoted higher prices on average, an effect that is driven by gender differences in the "uninformed" condition. Women who do not mention any benchmark price are quoted significantly higher prices than men in the same condition or women who mention the correct market price. However, once callers refer to a price, gender differences disappear for both informed and misinformed callers. We find some evidence that men do better in the uninformed condition than they do in the informed price condition; we find the opposite effect for women.

To test the effect of a cited benchmark price as a readily available reference in negotiations, we instructed callers to ask the repair shop for a price concession if the shop's initial price quote exceeded the benchmark price used in the relevant experimental condition ( $\$ 365$ or $\$ 510)$. In the condition where callers said initially that they did not know the market price, callers requested that the correct average market price $(\$ 365)$ be matched. We find that the average price concession, for consumers who receive a concession, is an $11 \%$ to $15 \%$ reduction relative to the originally quoted price, depending on the experimental condition. It is noteworthy that the average percentage reductions are similar whether or not the caller mentioned a benchmark price at the beginning of the call. However, only $26 \%$ of requests led to a price concession of any amount. We find that women are more likely by 11 percentage points than men to obtain a price concession at all. However, conditional on obtaining a price concession, the magnitude of the price concession does not vary by gender. 
When we combine our findings on initial price quotes and price concessions, our results suggest that women are best off demonstrating that they know the market price upfront. This lowers the initial quote while not negatively affecting any subsequent request to match. In contrast, our results suggest that men are better off inserting their price knowledge into the negotiation late: mentioning the market price upfront may increase the initial price quote, ${ }^{4}$ but does not increase the benefit of using it later to ask for a price concession.

After we finished collecting most of the data for the first experiment, we conducted a second experiment to see whether a "downward-biased" price condition (a claimed market price of $\$ 310$ ) would lead to a lower price than the uninformed condition for both men and women. We did not find that a downward-biased benchmark price changed prices relative to the uninformed condition.

As described above, the key contribution of our paper is its focus on the role that consumer price knowledge has on altering firm behavior. We can summarize what we believe our results indicate about the behavior of repair shops with regards to consumer price knowledge as follows. First, shops appear to respond to the available information about how well price-informed the caller is. When the caller disavows knowledge of prices, the shop must rely on its priors. If we group all callers together, it appears that shops assume that callers who cite no benchmark price know the market average price. However, if we split our analysis by the caller's gender, it appears that the shops have different priors about different genders, and that they infer that women are willing to accept a price that is higher than the price that men will accept. However, once a caller provides information about his or her price knowledge, the shops treat men and women the same, whether the information is that the caller's expectation is too high, too low, or correct. In other words, information about price knowledge supersedes for the shops any information they might infer from the caller's gender. In this sense, our results imply that our estimated gender effects are statistical discrimination rather than animus: shops don't quote women higher prices no matter what - they just believe that women will accept higher prices than men and respond accordingly. Finally, we find that women are more likely than men to be granted a price concession if they ask for one. We discuss possible reasons for this later in the paper in conjunction with the results themselves.

A key implication of our study is that consumers can use price knowledge strategically to affect price negotiations. Having a benchmark price in mind enables consumers to use bargaining strategies that they might otherwise not use, such as mentioning the benchmark price or negotiating for a price concession, which in turn may lead firms to offer different prices from what they would have offered otherwise. As we have shown, the extent to which benchmark prices help consumers depends on whether the benchmark prices accurately reflect market prices, how they are used, and

\footnotetext{
${ }^{4}$ We find this result in our main estimates, but the result does not hold up throughout all of our robustness checks.
} 
which consumer uses them.

Our paper proceeds as follows. In Section 2 we describe the connections between this paper and related research. In Section 3 we describe a theoretical framework for understanding how sellers respond to price inquiries, and how they might differentiate their responses according to their perceptions of different customers. In Section 4 we describe the experimental design and summarize the data. In Section 5 we present the findings from our experiments. Section 6 explores the robustness of our findings. We conclude in Section 7.

\section{Related literature}

Our paper connects to five literatures: negotiation and bargaining, reference prices, price knowledge, gender and race discrimination, and consumer price search. We discuss the connection between our paper and each of these literatures in turn.

There is a vast literature on negotiation. Tsay and Bazerman (2009) provide a review that emphasizes factors that lead to negotiated outcomes deviating from rational negotiation outcomes. There are a variety of such factors, including negotiators' social relationships, a negotiator behaving in an egocentric manner, negotiators' illusions about their own negotiation skills, negotiators' emotions, and their reliance on intuition. The section of this literature that most closely relates to our paper is that which examines the effect of information on negotiation outcomes. Stigler (1961) asserted the importance, in general, of price information. The effect of information on bargaining outcomes specifically is studied by Valley, Blount White, Neal, and Bazerman (1992), who find that, in a setting in which agents serve as information brokers between buyers and sellers, settlement prices are higher when the agent knows the buyer's maximum reservation price, and lower when the agent knows the seller's minimum reservation price.

Our study is unusual in this literature in that the experimental manipulation is not to vary the information setting, and then evaluate the equilibrium bargaining outcome that results from the two parties interacting. Instead, our experiment focuses on only a part of the negotiation process: namely, how the seller's offer differs depending on how informed about prices the buyer appears to be. We do this by having buyers operate from a script that keeps most of the buyers' side of the negotiation fixed across information conditions, leaving sellers' responses to the buyers' price inquiry as the only factor that varies across the information conditions.

The second literature to which our paper relates is reference prices. (See Biswas, Wilson, and Licata (1993), Kalyanaram and Winer (1995), and Mazumdar, Raj, and Sinha (2005) for reviews. $)^{5}$ Our paper is related to a part of this literature that studies the effect of reservation

\footnotetext{
${ }^{5} \mathrm{~A}$ large part of this literature is devoted to understanding how customers form reservation prices. In our
} 
prices on negotiations, such as Galinsky and Mussweiler (2001), Van Poucke and Buelens (2002), and Moosmayer, Schuppar, and Siems (2012). This literature has focused on identifying which of three possible references prices - the reservation price (the price at which the negotiator would be indifferent between accepting the offer and walking away), the aspiration price (the best expected result given the other negotiator), and the first offer price - has the greatest effect on the negotiated outcome. Since we are using scripts in which we fixed the benchmark prices that our callers present, and specify what the callers should say at every juncture in the script, our experiment really focuses on the effect that a buyer's reservation price has on sellers' responses (rather than on the final negotiated outcome). The seller's response certainly part of the overall price determination studied in other papers in this literature, our paper is unusual in that we have designed an experiment to isolate just this effect.

The third literature to which our paper is related is price knowledge (see Monroe and Lee (1999) and Anderson and Simester (2008) for reviews). Most of the papers in this literature focus on the short-term price knowledge of consumers for consumer packaged goods. In contrast to these papers we don't measure price knowledge. Instead, we are interested in firms' reactions to the price knowledge that consumers convey to them.

The fourth literature to which our paper is related is consumer price search. In models of consumer price search, a literature initiated by Stigler (1961), price dispersion can arise in equilibrium if consumers vary in how costly it is for them to search (Stahl 1989, Anderson and de Palma 2005). Optimizing consumers will employ a search rule in which they continue searching as long as the expected gain to an additional search is worth the cost of conducting an incremental search. In practice, this translates to a "reservation price" rule in which consumers search until they find a price that is below their "reservation price." (In this context, a "reservation price" should be though of as "walk-away" price rather than as maximum willingness-to-pay.) On the other side of the market in these models, firms who are choosing prices make a trade-off that closely resembles the monopoly pricing trade-off: a higher price increases the profits made on each individual sale, but also increases the possibility that the price is above a potential buyer's reservation price, and hence reduces the probability of making a sale. Salop (1977) shows that consumers with higher search costs will have higher reservation prices. Thus, if a firm can identify which consumers are likely to have high vs. low search costs, it should charge higher prices to high search cost consumers.

The final literature to which our paper is related is gender and race discrimination. The aim of many of the papers in this literature is to understand whether one set of customers (distinguished by gender or race) is able to obtain lower prices than another. Castillo, Petrie, Torero, and Vesterlund

experiment, the experimental design specifies reservation prices for our callers to present as their own, which means that this is not the part of the reference price literature that is relevant for our paper. 
(2013), Ayres and Siegelman (1995) and Gneezy, List, and Price (2012) are three examples. While our paper does investigate the effect of gender on price, our emphasis differs from most of the papers in this literature in that we are interested primarily in whether the effects of different information conditions vary by gender; put simply, we are interested more in the interaction than in the main effect of gender.

The analysis that is most closely related to ours is in Gneezy, List, and Price (2012). Gneezy, List, and Price (2012) contains a series of field experiments across several different markets, and investigates not only discrimination by race and gender, but also by age, sexual orientation, and disability. In their investigation of disability discrimination, they have disabled and non-disabled testers ask for price quotes at auto body shops using an identical car. Their experiment is small (72 price quotes obtained from 36 repair shops.) Nevertheless, they find that disabled consumers are quoted prices that are higher by $30 \%$ compared to non-disabled consumers. The authors attribute this result to the differences in perceived search costs between the two groups. In an effort to support this claim, the authors conduct an additional experiment in which they instruct their testers to add to their original script the line "I'm getting a few price quotes," to signal that search costs of disabled and abled are similar. Unfortunately, this follow-up experiment is an even smaller sample (24 repair shops), and the results are inconclusive. However, the interaction between customer characteristics (in this case disability rather than gender) and a search cost signal is related to the effect we investigate in this paper.

In terms of empirical setting, our paper is related to Schneider (2012) who also conducts a field experiment in the context of auto repair, although his paper is interested in the issue of over- vs. under-treatment in the diagnoses offered by repair shops, not price quotes.

\section{Theoretical Framework}

In this section we outline a very simple model of how a seller might respond to price inquiries from potential customers. The purpose of our model is to motivate and to help us interpret the empirical comparisons we will make in our field experiment.

\subsection{Uniform buyers}

Suppose that buyers have unit demands. Further suppose that each buyer's reservation price is drawn from a distribution $F(p)$. The reservation price should be understood as in Salop (1977), i.e. as a "walk-away" price rather than a measure of the consumer's utility from the purchase. In other words, a buyer will buy from this seller if the buyer is offered a price less than or equal to the 
buyer's reservation price; otherwise, the buyer will keep searching and not buy from this seller. ${ }^{6}$ Suppose that the seller knows the distribution of reservation prices, but not the reservation price of any individual buyer. Suppose also that the seller produces at a constant marginal cost of $c$.

If a seller quotes a buyer a price of $p$, then with probability $F(p)$ the buyer's reservation ("walkaway") price is below $p$, and the buyer will not buy. With probability $1-F(p)$, however, the buyer's reservation price is above the quoted price $p$ and the buyer will buy. Thus, the seller's expected profit if the seller quotes a price of $p$ is

$$
\Pi(p)=F(p) \cdot 0+[1-F(p)] \cdot(p-c)=[1-F(p)] \cdot(p-c) .
$$

We assume that $\Pi(p)$ is strictly concave in $p .^{7}$

Note that since $F()$ is monotonically increasing in $p$, this problem is analogous to the problem of a monopolist facing a downward sloping demand curve given by $1-F(P)$. The seller's profitmaximizing price quote can be solved from the first order condition:

$$
\frac{\partial}{\partial p} \Pi(p)=-f(p) \cdot(p-c)+[1-F(p)]=0
$$

Rearranging terms allows us to write an implicit expression for the profit maximizing price as follows:

$$
\left(p^{*}-c\right)=\frac{1-F\left(p^{*}\right)}{f\left(p^{*}\right)} .
$$

Note that if we divide both sides of equation 3 by $p$, we can transform the expression into the familiar form that relates percentage markups to the elasticity of demand: $\frac{p-c}{p}=\frac{1-F(p)}{p} \cdot \frac{1}{f(p)} \cdot 8$

\subsection{Two types of buyers}

Now suppose that there are two types of potential customers, and that the reservation prices of the two types are drawn from different distributions. The reservation prices of the first type of customers (type L, who can be thought of as the low reservation price customers) are drawn from the distribution $F^{L}(p)$. The reservation prices of the second type of customers (type H, who can be thought of as the high reservation price customers) are drawn from the distribution $F^{H}(p)$.

\footnotetext{
${ }^{6}$ In our simple framework, the seller makes a take-it-or-leave it offer. There is an extensive literature the investigates the effect of initial offers, price knowledge, and reservation prices on negotiated outcomes. See the literature review in Section 2 for references.

${ }^{7}$ The uniform distribution is one example of a reservation price distribution $F(p)$ that would yield a strictly concave profit function.

${ }^{8}$ In this formulation, $1-F(p)$ is the probability that the buyer purchases and is the analog to $q . \quad f(p)$ is the change in the probability of purchase as a function of $p$, analogous to $\frac{\partial q}{\partial p}$, making the whole right hand side of the expression analogous to $\frac{1}{\left|\epsilon_{d}\right|}$ in the inverse elasticity rule.
} 
Suppose that $F^{L}$ and $F^{H}$ can be stochastically ordered, and that $F^{H}$ hazard rate dominates $F^{L}$, meaning that $\frac{1-F^{H}(p)}{1-F^{L}(p)}$ is increasing in $p .^{9}$

In our context, one could think of these differences in reservation price distributions as arising from differences in search costs between customer types. Customers who have high search costs (because they have inherent disutility of search activity, because they have little product knowledge, or because the biases or beliefs of sellers makes it hard for them to obtain low prices) will generally have higher reservation prices than customers with low search costs (see Salop (1977)). Thus, we can think of type $\mathrm{H}$ customers as high search cost customers.

If a seller knew a potential buyer's type ( $\mathrm{L}$ or H) for sure, then the seller's expected profit from quoting a price $p$ to a customer of type $i$ would be $\Pi^{i}(p)=\left[1-F^{i}(p)\right] \cdot(p-c)$, which we assume as in section 3.1 is strictly concave.

In our empirical context, sellers - auto repair shops - do not know the types of the individual customers they encounter, but they receive two signals that they can use to infer information about customer types. One is the gender of the customer. The other is that the customer may or may not cite a benchmark price (in the latter case we say the caller is uninformed), and if the caller does cite a benchmark price, that price may be close to or far away from the average market price (we say the caller is informed in the former case and misinformed in the latter case).

We describe these information signals in more detail in the next section. For now, we suppose simply that a seller does not know the type of a potential buyer and that on the basis of the signals the seller assigns probability $\alpha \in(0,1)$ to the buyer being of type $\mathrm{H}$ and probability $1-\alpha$ to the buyer being of type L.

With two possible types of buyers, if the seller quotes a price of $p$ to a buyer, then with probability $\alpha \cdot F^{H}(p)$ the buyer is of type $\mathrm{H}$ and has a reservation price below $p$ while with probability $(1-\alpha) \cdot F^{L}(p)$ the buyer is of type $\mathrm{L}$ and has a reservation price below $p$. In either of these cases, the buyer will not buy. This means that the seller's expected profit from quoting price $p$ to a buyer whom the seller believes with probability $\alpha$ to be type $\mathrm{H}$ is

$$
\Pi(p, \alpha)=\alpha \Pi^{H}(p)+(1-\alpha) \Pi^{L}(p)=\alpha\left[1-F^{H}(p)\right] \cdot(p-c)+(1-\alpha)\left[1-F^{L}(p)\right] \cdot(p-c) .
$$

We wish to show that $p^{*}(\alpha)$, the optimal price for the seller to quote if the seller assigns probability $\alpha$ to the buyer being type $\mathrm{H}$, is increasing in $\alpha$. Because we have not specified a particular functional form for $F()$, we cannot solve explicitly for $p^{*}(\alpha)$. Instead our approach will be to use the implicit function theorem to sign the derivative of $p^{*}$ with respect to $\alpha$.

\footnotetext{
${ }^{9}$ Distributions that can be stochastically ordered in the sense of a hazard rate dominance could differ from each other in both mean and variance.
} 
We begin by noting that we can characterize the optimal price for the seller to quote using the first order condition of equation 4 with respect to $p$, which we label $\phi(p, \alpha)$ for future reference.

$$
\phi(p, \alpha)=\alpha\left\{\left[1-F^{H}(p)\right]-f^{H}(p) \cdot(p-c)\right\}+(1-\alpha)\left\{\left[1-F^{L}(p)\right]-f^{L}(p) \cdot(p-c)\right\}=0
$$

While we cannot solve this expression explicitly for $p^{*}$, we can use the implicit function theorem to obtain the derivative of $p^{*}$ with respect to $\alpha$. In particular, the implicit function theorem implies that

$$
p_{\alpha}^{*}=-\frac{\phi_{\alpha}}{\phi_{p}}
$$

where the subscripts denote derivatives. If we can $\operatorname{sign} \phi_{\alpha}$ and $\phi_{p}$, we can sign $p_{\alpha}^{*}$.

Since $\phi(p, \alpha)$ is the first order condition of $\Pi(p, \alpha)$ with respect to $p, \phi_{p}$ is the second order condition and therefore negative (since $\Pi(p, \alpha)$ is strictly concave in $p) .{ }^{10}$ The sign of $p_{\alpha}^{*}$ will therefore be the same as the sign of $\phi_{\alpha}$. In the appendix we show that the assumption that $F^{H}(p)$ hazard rate dominates $F^{L}(p)$ implies that $\phi_{\alpha}$ is positive. This in turn means that $p^{*}(\alpha)$ is increasing in $\alpha$, or in other words that the optimal price for a seller to quote to a buyer of unknown type is increasing in the probability the seller places on the buyer being of the high reservation price type.

For the purposes of interpreting our field experiment, the key result that we take away from this model is that sellers will quote higher prices to buyers whom they believe to be more likely to have higher reservation prices (in the sense of hazard rate dominance). In particular, any information that sellers can glean from buyers that is correlated with reservation prices should be used by sellers in setting prices. In our field experiment, we will give sellers two pieces of information that could indicate something about reservation prices, gender and a signal of price knowledge. It is an empirical question whether either is considered by sellers to be a useful signal of reservation price, but if either (or both) are, we would expect to see one (or both) used by sellers in setting prices.

\subsection{Signals of buyer type}

In this subsection, we describe in general terms how our theoretical framework relates to our experimental design. We describe the specifics of the experiment in detail in Section 4.

One of the information signals that the seller receives is of the buyer's gender. There are a variety of reasons to think that a seller (a repair shop, in our case) might believe that a woman has a higher reservation price (meaning a "walk-away" price) than a man for the same product or service. While search costs can be understood as the disutility or opportunity cost of time spent searching, or of the financial cost of accessing information sources, Salop (1977) argues that search

\footnotetext{
${ }^{10}$ This is because $\Pi(p, \alpha)$ is a linear combination of two functions that are strictly concave in $p$.
} 
cost could also be understood more broadly. He says, "Consumers may differ in effective search costs due to differences in their abilities to analyze and process data gathered. A consumer with an incorrect prior on [the distribution of prices offered in the market] may also be treated as having a higher [search cost]. One can think of high cost consumers simply as being less adept in economic decision making." Conventional wisdom is that women on average have less knowledge about some product categories (such as cars) than men do, which may make them less able to judge whether a quoted price is fair, reasonable, or reflective of the market price. There is also conventional wisdom that women are less adept or less aggressive negotiators, which may mean that they are more willing to accept a high price than a man is on average. Finally, the process of interacting with sellers that hew to such conventional wisdom may make the process of price inquiry more unpleasant for women than men, raising a woman's disutility from the process relative to that of a man with whom she has equal product knowledge or bargaining skill. In other words, women's higher search costs could arise endogenously from the beliefs (or biases) of repair shops. Any of these search costs will shift the distribution of women's reservation prices upward relative to those of men.

The other information signal that the seller receives is related to a benchmark price. We consider three conditions related to benchmark prices: buyers can be uninformed, informed, or misinformed. In our experiment, buyers indicate that they are correctly informed, which we call simply "informed," by communicating that they know what the average market price is. They indicate that they are misinformed by citing a price that is significantly higher than the market price as what they believe that average market price to be. They indicate that they are uninformed by communicating that they don't know what the market price is.

We would expect that a buyer who is misinformed will be believed by repair shops to have higher reservation prices than callers who are (correctly) informed. If a buyer believes that the market price is higher than it really is, then the seller can quote a price that is higher than the true market price without the buyer concluding that she is likely to do better elsewhere.

We are somewhat more agnostic about what sellers will believe about a buyer who is uninformed. One could argue that a seller should, in the absence of any specific information about the customer's belief about the market price, assume that the customer knows the average market price. However, we think it is more likely that a buyer who says explicitly that he or she doesn't know anything about the market price will be assumed by a seller to have relatively high search costs, and therefore to be more likely to have high reservation prices than a buyer who is informed.

In terms of the model, the seller must assess $\alpha$ (the probability that the buyer is of type $\mathrm{H}$ ) in six different scenarios (a female buyer who is uninformed, informed, or misinformed, and a male buyer who is uninformed, informed, and misinformed). We denote these six $\alpha$ 's as $\alpha_{\text {Uninformed }}^{W}$, 
$\alpha_{\text {Informed }}^{W}, \alpha_{\text {Misinformed }}^{W}, \alpha_{\text {Uninformed }}^{M}, \alpha_{\text {Informed }}^{M}$, and $\alpha_{\text {Misinformed }}^{M}$

In our experiment, we will gather data on actual price quotes offered to callers in each of these scenarios. This will enable us to draw inferences about what repair shops infer (on average) about the probability that customers in each condition are drawn from a high vs. low distribution of reservation prices. These comparisons will also allow us to draw inferences about whether and to what extent repair shops use each of the signals available to them (gender and price knowledge) in choosing repair quotes.

\subsection{Empirical predictions}

The relationship between the six $\alpha$ 's is an empirical question. (Indeed, it is the empirical question of this paper.) However, we have predictions about comparisons between different pairs.

First, given the conventional wisdom about women and car repair, we would expect that within an information condition repair shops will believe that a female caller is more likely to have a higher distribution of reservation prices (in the sense of hazard rate dominance) than a male caller. In other words, we would predict that $\alpha_{\text {Uninformed }}^{W}>\alpha_{\text {Uninformed }}^{M}$, that $\alpha_{\text {Informed }}^{W}>\alpha_{\text {Informed }}^{M}$, and that

$\alpha_{\text {Misinformed }}^{W}>\alpha_{\text {Misinformed }}^{M}$ Using our model in Section 3.2, we can translate these predictions into empirical predictions about the average price quotes we would expect shops to offer to callers in each of these categories. In particular, we would expect that women would be quoted higher prices on average in each of the information conditions. These comparisons are depicted graphically in Figure 1.

We would also predict that for either gender, citing a price of $\$ 510$ will lead the shop to believe that the caller's reservation price is drawn from a higher distribution of reservation prices than citing a price of $\$ 365$. In other words, we would predict that $\alpha_{\text {Misinformed }}^{W}>\alpha_{\text {Informed }}^{W}$ and $\alpha_{\text {Misinformed }}^{M}>\alpha_{\text {Informed }}^{M}$. In addition, our prediction is that disavowing knowledge of a market price will lead shops to believe that a caller is drawn from a higher distribution of reservation prices than citing a market price of $\$ 365$. In other words, $\alpha_{\text {Uninformed }}^{W}>\alpha_{\text {Informed }}^{W}$ and $\alpha_{\text {Uninformed }}^{M}>\alpha_{\text {Informed }}^{M}$. In terms of average price quotes, this implies that the average price quotes in the misinformed condition and in the uninformed condition will be higher than average price quotes in the informed condition, for both men and women. These empirical predictions are depicted graphically in Figure 2.

In our experiment, after the callers receive an initial quote from the shop, they ask the seller to match a benchmark price if their benchmark is lower than the initial quote. Notice that no gender information changes in the process of asking for a price concession. However, the request for a price concession may signal something additional to repair shops about the caller's price knowledge.

In the uninformed condition, the caller asks the shop to match the market price of $\$ 365$ if the 
initial quote is higher than $\$ 365$. By specifying this price, callers reveal to the shop that they are actually informed about average market prices. Recall that we predicted earlier that disavowing knowledge of a market price will lead shops to believe that a caller is more likely to be drawn from a high distribution of reservation prices than citing a market price of $\$ 365$. Hence, we predict that asking for a price concession will lead shops to decrease their estimate of the probability that a caller is drawn from a high distribution of reservation prices. In other words, $\alpha_{\text {Uninformed, } 0}^{W}>\alpha_{\text {Uninformed,1 }}^{W}$ and $\alpha_{\text {Uninformed, },}^{M}>\alpha_{\text {Uninformed, } 1}^{M}$ where 0 refers to the shop's estimate of $\alpha$ at the time of the initial price request (before a request for a price concession) and 1 refers to the shop's estimate of $\alpha$ after the request for a price concession. We predict that since asking for a price concession in the uninformed condition reduces $\alpha$, we should expect to see shops (on average) offering price concessions when one is requested.

In the informed and misinformed condition, the benchmark price that the caller asks the shop to match is the $\$ 365$ or $\$ 510$ price that the caller has already cited. (Having stated this benchmark price before asking for a price quote is what defines the informed and misinformed conditions.) The question we must consider, therefore, is whether referring again to this same price causes the repair shop to update its beliefs about whether the caller is likely to be a high reservation price or a low reservation price type customer. While citing the same price does not reveal anything new about the customer's information, it does reveal something about the customer's disutility of bargaining. In our model, the differences in the reservation price distributions of different consumer types were predicated fundamentally on differences in search costs, as described in section 3.3. Thus, the willingness of a caller to continue to negotiate on price should suggest that the consumer is less likely to be of the high reservation price than was indicated by the benchmark price the caller cited alone. We would thus expect that in both the informed and misinformed conditions, the shop should lower its estimate of $\alpha$ after the caller asks for a price concession, and should therefore (on average) offer a lower price. In the terminology of the model, we would expect $\alpha_{\text {Misinformed,o }}^{W}>\alpha_{\text {Misinformed,1 }}^{W}$ and $\alpha_{\text {Misinformed, } 0}^{M}>\alpha_{\text {Misinformed, } 1}^{M}$ as well as $\alpha_{\text {Informed, } 0}^{W}>\alpha_{\text {Informed, } 1}^{W}$ and $\alpha_{\text {Informed, } 0}^{M}>\alpha_{\text {Informed, } 1}^{M}$ where 0 again refers to the shop's estimate of $\alpha$ at the time of the initial price request (before a request for a price concession) and 1 refers to the shop's estimate of $\alpha$ after the request for a price concession. Overall, across all three information conditions we would expect shops to lower their initial quote following a request from the caller to match a benchmark price.

\section{Experiment}

We conducted our experiment in cooperation with the company AutoMD.com, an online firm that helps consumers diagnose car problems and provides consumers with information on auto repair 
costs in the United States. ${ }^{11}$ In order to provide repair cost estimates to consumers, AutoMD operates a call center in which agents call local repair shops and ask for price quotes for specific types of repairs. For that purpose, agents may or may not introduce themselves as employees of AutoMD, and may at times mention AutoMD's estimated prices to shops. AutoMD allowed us to prepare a set of scripts for calls that varied the information that their call center agents provided in order to create a set of experimental treatment and control conditions. AutoMD instructed its agents to make calls following the scripts and to randomize which scripts they used for which calls according to a randomization protocol we designed. Conducting our scripted calls was very similar to what agents regularly did in their jobs. They incorporated our experimental calls into their normal workflow, and were paid their regular salary by AutoMD. The call center consisted of nine agents, of which four were males and five were females, who conducted our assigned calls over a period of 16 weeks between June 11 and October 5, 2012.

We instructed the agents to request a price quote for a radiator replacement for a 6-cylinder 2003 Toyota Camry LE. We chose this model because it was one of the vehicles in the AutoMD database for which consumers most frequently requested information on repair costs. ${ }^{12}$ We chose a radiator replacement because radiator leaks are relatively common among 10-year-old vehicles, and because radiator leaks are easily diagnosed by consumers. We held the car model, model year, and repair constant across all conditions and weeks of the experiment. The estimated average price in the AutoMD database for a radiator repair for this specific model and model year was $\$ 365$, with some regional variation. The repair shops in this study were independent shops and shops affiliated with national/regional chains. To reduce the variance of quoted prices we did not call car dealerships, which generally quote much higher prices than other repair shops.

\subsection{Main experiment}

In our main experiment we randomly assigned repair shops and call center agents to one of three experimental conditions. These conditions were codified in the form of call center scripts that the agents were instructed to follow as closely as possible. In the first script, after introducing themselves with, "Hello, my name is John/Jennifer," agents said, "So I have a 6-cylinder 2003 Toyota Camry LE. I just visited the website AutoMD.com, and for this area they say the cost should be \$365 to replace the radiator on my car. Could you tell me how much you charge?" We refer to this script as the "informed" condition.

\footnotetext{
${ }^{11}$ Any results and conclusions contained in this paper are solely the responsibility of the authors and do not necessarily reflect the views of AutoMD.com nor are they endorsed by AutoMD.com.

${ }^{12}$ In addition, in unrelated vehicle purchase data to which we have access, this model does not stand out relative to other cars in how many buyers are male or female.
} 
In the second script, after introducing themselves, agents said, "So I have a 6-cylinder 2003 Toyota Camry LE. I have no idea how much it is to replace a radiator. Could you tell me how much you charge?" This is the "uninformed" condition.

In the third script, again after introducing themselves, agents said, "So I have a 6-cylinder 2003 Toyota Camry LE. I just visited the website AutoMD.com, and for this area they say the cost should be $\$ 510$ to replace the radiator on my car." We refer to this condition as the "misinformed" condition. (See page Web Appendix-1 for an outline of the scripts used by the agents.)

We chose the price in the informed condition to signal that the consumer was aware of the prevailing market price. In the misinformed condition we wanted to signal that the caller had inaccurate information. In consultation with AutoMD.com we chose $\$ 510$ because it was substantially higher than $\$ 365$ (by $40 \%$ ) but not so high that it would be impossible for a repair shop to have given such a quote. We chose the wording in the uninformed condition to signal that the consumer was not informed about prices in the market and had no benchmark price in mind.

After agents received a price quote, they asked shops to make sure that the price included parts, labor, and antifreeze and was the total price before tax. The agents then recorded the price quote that incorporated any adjustments for these elements. We refer to this price as the "initial price quote."

Next, agents were instructed to compare the initial price quote to the benchmark price they had mentioned at the beginning of the call in the informed or misinformed condition ( $\$ 365$ or $\$ 510$ ). If the initial price quote exceeded the respective benchmark price, agents said, "So, I have a question. Would you match the price of $\$ 365$ (or $\$ 510$ ) that the website AutoMD said it should cost in this area?" Agents would then record "no," "yes," or a revised price offer if the shop offered a price concession that differed from a match of the benchmark price. We also had agents ask for a price concession in the uninformed condition by saying, "So, I have a question. I just visited the website AutoMD.com, and for this area they say the cost should be $\$ 365$. Would you match this price?" Doing so allowed us to later determine whether callers were better off mentioning the benchmark price at the outset of the call (informed condition) or after the initial price quote (uninformed condition). The agents concluded the call after obtaining a response to the request for a price concession or - if the initial price quote was below $\$ 365$ or $\$ 510$, depending on the condition - after obtaining the initial price quote.

Agents were provided with weekly spreadsheets containing a list of shops to call for each day of the week, and a script assignment for that shop. In order to minimize agent error in following the script, we assigned agents to use the same script for all the calls they made in a given day (although agents used different scripts on different days). Calls were made during weekdays. Shops were randomly assigned across agents. In order to study within-shop variation, we tried to obtain 
two price quotes from each shop, with a randomly assigned pair of scripts in random order, keeping at least four weeks between the two calls. ${ }^{13}$ We chose to have both calls to any given shop made by agents of a single gender; the purpose was to be able to measure differences between information conditions with less variance. We decided on the number of shops to call before the start of the experiment and ended the experiment once we had exhausted our list of shops. The list of repair shops consisted of all non-dealership repair shops in the US recorded by AutoMD as providing radiator replacements for Toyota vehicles in Designated Market Areas (DMAs) with 150 or more repair shops in the United States. These 22 DMAs correspond to the most heavily populated DMAs in the country.

We collected quotes from a total of 2,778 shops over a period of 16 weeks. Of these, 1,825 provided price quotes under two different experimental conditions. We obtained only one quote from the remaining shops because the shop could not be reached a second time, the shop closed, or the shop refused to provide a quote over the phone despite having done so in a previous call under a different information condition. Overall, we obtained 4,603 price quote observations in our main experiment. $^{14}$

\subsection{Experiment 2}

After collecting data for 10 weeks we were told that there was enough call center capacity to add a "downward-biased" condition. We chose $\$ 310$ for the downward-biased benchmark price, which corresponded to the 20th percentile of the initial price quotes we had collected so far in the uninformed condition.

Since our original list of shops from DMAs with 150 or more shops would be exhausted in the process of completing our ongoing main experiment, we used a new list of shops for our calls in experiment 2, this time from DMAs with 70 to 149 repair shops. These calls began in week 12. As a result, experiment 2 was based on shops in different, smaller, markets and in different, later, weeks than our original experiment (henceforth experiment 1). Because we knew that we could not consider the conditions in which we collected observations in experiment 1 to be experimentally valid counterfactuals for the downward-biased condition in experiment 2 , in experiment 2 we replicated the uninformed condition along with the downward-biased condition. This way we had one experimentally valid counterfactual for the downward-biased condition.

Overall, both experiments ran concurrently for three weeks. During that time the agents made second calls to shops in experiment 1 and also called repair shops from experiment 2 using the un-

\footnotetext{
${ }^{13}$ We asked agents to record if a shop indicated that they noticed that we had called before. We recorded only 94 such occasions among the 4,603 total quotes.

${ }^{14}$ We obtained an additional 85 quotes but removed them from the analysis because agents had erroneously used a pre-test version of the call script. See the robustness section of the web appendix for a detailed discussion.
} 
informed and downward-biased conditions. In experiment 2, we collected 1,941 price quotes across the two conditions. Table 1 summarizes the differences across conditions in the two experiments.

\subsection{Discussion}

In this subsection we discuss the limitations of our experiment.

\subsubsection{Interpretations of the uninformed condition}

We wrote the script for the "uninformed" condition so that it would emphasize that agents had no information about prices when requesting a price quote. Specifically, in the script for this condition we did not ask agents to say: "So I have a 6-cylinder 2003 Toyota Camry LE. Could you tell me how much you charge?" since this would have left open to the shop's interpretation what price knowledge the caller had. Instead, we asked agents to say: "So I have a 6-cylinder 2003 Toyota Camry LE. I have no idea how much it is to replace a radiator. Could you tell me how much you charge?"

One might be concerned that the phrase "I have no idea" did not lead shops to fall back on their beliefs about search costs and reservation prices among men and women in the overall population, but that it instead communicates some kind of more specific information.

For example, if shops interpret "I have no idea" to mean "I am just starting my price search process," then the statement gives shops little to go on except their beliefs about the distribution of prices by gender in the overall population. Alternatively, shops may believe that there is little to be gained by offering a low price to someone who doesn't know enough about market prices to recognize it as a low price. If so, consumers who say "I have no idea" may be quoted higher prices than those who show greater price knowledge.

If "I have no idea" is interpreted to mean "I have unusually high search costs" or "I have lower than average price knowledge" then consumers who say this should be quoted higher prices than consumers in the informed condition.

If "I have no idea" is interpreted as "I probably have some idea, but I am withholding it strategically," it is unclear what shops should think about these customers relative to customers who cite a benchmark price of $\$ 365$. Perhaps they are extra-savvy and extra-cagey, or perhaps they haven't yet gotten price information they think can be used as a useful benchmark price. If the caller's gender interacts with the statement in shops' interpretation-for example, men who say "I have no idea" are believed to be very strategic while women who say this are believed to be very naive - that would lead to higher price quotes for women than men in this condition.

The empirical results of our field experiment will be consistent some of these interpretations and inconsistent with others. We defer further discussion until Section 5. 


\subsubsection{Other limitations}

When evaluating the external validity of our field experiment, one should consider some of the constraints of our experimental parameters. First, nine agents from the call center were available to make the experiment calls. While a larger number of callers may have been desired, these agents were all trained in making "mystery shopper" calls and following scripts. Ideally, the trained agents vary only in the signals they give shops, namely the gender and how informed they appear to be about prices. Second, to assure we have a large enough sample of calls, we had to limit our investigation to a single type of repair. As described above, we chose a repair that would be standard and simple to detect in order to reduce potential variance between quotes due to the repair type alone and to make our callers seem believable. Picking a standard repair (as opposed to an uncommon one, or one whose cost to execute is variable) would potentially work against differences among the various conditions if the price quote is also standardized. The fact that we still find differences in quoted prices despite picking a standard repair strengthens the robustness of our findings. Finally, our scripts mention prices obtained on AutoMD.com (and not prices quoted by competing stores, for example). We cannot determine with our experiment whether mentioning prices of competing stores versus mentioning prices of a third party website would yield different results.

Another caveat is that our investigation involved only quoted prices and not prices paid. One might be concerned that differences in quoted prices will not reflect differences in transaction prices since repair shops can deviate from the price they have quoted once a consumer actually brings the car in for repair. Notice, however, that shops have incentives not to deviate too much from their quoted prices for two reasons. First, a shop that quotes a price that is higher than they actually plan to charge - perhaps to "delight" the customer once they come in-risks losing business to other shops if consumers make their choice of shop based on the quoted price. Second, a shop that quotes a price that is lower than they actually plan to charge - a "bait and switch" strategy - risks making consumers feel "ripped off" and losing repeat business. This means that, while quoted price need not exactly correspond to eventual transaction prices, there are strong economic incentives for repair shops for the two not to deviate too much. Even if there are systematic differences between quoted and actual prices, this would only invalidate our results if the differences themselves differ systematically across conditions.

\subsection{Experimental paradigm}

The experiments used in this paper follow an experimental paradigm commonly used to study race and gender discrimination (Ayres and Siegelman 1995, Bertrand and Mullainathan 2004, Gneezy, 
List, and Price 2012). In this paradigm researchers pose as consumers/job seekers to measure the reaction of firms to different experimental stimuli. By design, firms cannot give informed consent without invalidating the purpose of the experiment. Because researchers typically do not end up engaging in a purchase or taking a job, this experimental paradigm imposes costs on firms. As a result, researchers have to be mindful to balance the benefits from the insights of the experiments with the costs imposed on firms.

While this is fundamentally a subjective judgment, we believe that the cost imposed by this experiment on a repair shop was small, for three reasons: First, these shops receive calls on a regular basis from "mystery shoppers" (a term used in the industry to refer to the practice of agents of firms pretending to be a consumer in order to obtain price and/or product information). In fact, the business model of AutoMD and its competitors is based on sampling prices for various repairs and vehicles from repair shops. While our script prescribed specific wording, calls made during the experiment did not differ in nature from calls made by AutoMD call center agents on a daily basis. Second, we picked a standard repair to ensure that shops would not have to engage in time-intensive research for a quote. In fact, the duration of our calls was short-typically three minutes or so. Third, our calls were unlikely to have further consequences for these firms. (Our calls were not made in high enough volume to trigger updated estimates of anticipated demand, nor were they likely to trigger an emergency response by firms such as might be caused by reports of food poisoning in restaurants, for example.)

\section{Results}

In this section we report on the results of our main experiment. We begin with an analysis of how communicating different degrees of price knowledge affects the initial price quote given to a consumer, a variable we label PriceQuote. Next, we analyze how the effect of communicating different degrees of price knowledge differs by gender. We then show how firms react when consumers request that the firm match their benchmark price. Finally, we report the results of the downward-biased price condition, added in our second experiment.

\subsection{Comparing different price knowledge conditions}

The distributions of initial price quotes in our main experiment are graphed in Figure 3 on page 43. Consumers in the uninformed condition, who communicated no benchmark price, were quoted a price of $\$ 394.5$ on average; the median initial quote was $\$ 375$. If consumers communicated that they were informed about the market price by citing a benchmark price of $\$ 365$, the average price quote 
was $\$ 392.5$ (median $\$ 370$ ). ${ }^{15}$ Consumers in the misinformed condition, who cited a benchmark price of $\$ 510$, received an average initial price quote of $\$ 427$ (median $\$ 425$ ).

To analyze whether the price quotes are statistically different from each other in the three conditions, we estimate the following specification:

$$
\text { PriceQuote }_{i j t}=\alpha_{0}+\alpha_{\mathbf{1}} \text { Condition }_{\mathbf{i}}+\alpha_{\mathbf{2}} \text { Controls }_{\mathbf{i j t}}+\epsilon_{i j t}
$$

PriceQuote is the initial price quote obtained from shop $j$ called under condition $i$ in week $t$. Condition contains indicator variables for the different information conditions. The omitted category is the informed condition. While the randomization of repair shops to conditions and call center agents should make control variables unnecessary, we use control variables in Controls as a randomization check and to convince ourselves of the robustness of our findings. In different specifications we will control for week fixed effects, DMA fixed effects, call order fixed effects, and repair shop fixed effects.

The results of estimating Equation 7 with varying controls are reported in Table 2 on page 37 . Column 1 shows the results of a specification without control variables, which corresponds to a test of whether the means in the histogram are different from each other. We find no difference in the average prices quoted to callers between the uninformed and the informed conditions. However, consumers in the misinformed condition were quoted prices that were higher by $\$ 34$ on average than consumers in the informed condition $(p<0.01)$. In columns 2 and 3 we report the results of estimating Equation 7 with week fixed effects only, or week and DMA fixed effects. The results in column 2 and 3 indicate that our randomization of shops to conditions worked well - the estimates of the experimental effects are close to unchanged by the addition of these controls. Column 4 also includes an indicator for whether the price quote was obtained from a shop that had already been called once before under a different condition. While the coefficient on SecondCall in column 4 suggests that shops quoted higher prices when they had been called before, the coefficients on the condition indicator variables suggest that this does not change the estimated difference between conditions.

As we described in Section 4, we tried to call each shop twice. In practice, some shops could not

\footnotetext{
${ }^{15}$ Note that while the median price in these conditions is very close to the $\$ 365$ benchmark price cited by callers in our informed condition, the average price is somewhat higher than $\$ 365$. There are two possible reasons for this. First, AutoMD had somewhat sparse data for this particular vehicle-repair combination and therefore might have underestimated the true market price due to sampling error (after the experiment we tried to obtain the raw data used to create the estimate but it was no longer available). Second, to make sure that individual price quotes in the experiment were as comparable as possible, we instructed agents to request a price quote including antifreeze liquid and a cooling system flush instead of leaving it up to the shops' judgment whether these should be included in the initial quote or not. These might not have been included consistently in the data AutoMD used to estimate the market price.
} 
be reached a second time or simply refused to give a quote when we called them the second time. As a result, 953 of the 4,603 quotes in our main experiment are from shops that only quoted one price. For the remaining 3,650 price quotes we can add another control, namely, repair shop fixed effects. ${ }^{16}$ Column 5 reports the results of this regression. As before, we find no difference in the prices quoted to callers between the uninformed and the informed conditions. In addition, we still find that callers in the misinformed condition were quoted, on average, more than consumers in the informed condition, although we estimate an effect of $\$ 24$ when we include shop fixed effects, which is smaller than the $\$ 35$ effect estimated in columns 1-4. The fact that our qualitative results don't change when we include shop fixed effects suggests that, on average, shops don't directly quote from a price list (if they did we would not observe price quote differences between conditions). In fact, it seems that quoting individualized prices is the norm among shops: only 178 of the 1825 shops that provided us price quotes under two different experimental conditions quoted the same price in both conditions. This result is not restricted to independent repair shops. For the three largest chains in our sample we found that only 8 of 132, 1 of 62 , and 0 of 56 shops within each chain quoted the same price in both conditions. These figures are larger but still small (less than a quarter of the sample) if we define the prices across the two calls as being "the same" if they are within $\$ 1$ or within $\$ 10$.

In summary, we find that communicating a benchmark price that exceeds the market price ("misinformed" condition) induced repair shops to provide price quotes that were higher by $\$ 24$ to $\$ 35$ than when a market-based benchmark price or no benchmark price was communicated. The main inference we draw from this result is that shops change the prices they quote in response to information communicated to them by potential customers. In particular, if a customer indicates that he or she believes that the market price is substantially higher than it really is, the shop will try to capitalize on that by quoting a higher price. This inference is particularly strong because it holds in a within-shop comparison (column 5, which includes repair shop fixed effects). However, we find no difference in average price quotes between our informed and uninformed conditions. One possible interpretation of this result is that repair shops, without any information about consumers' price knowledge, infer that everyone has a benchmark price that corresponds to the market price. We will argue next, in our presentation of gender effects, that this interpretation appears to be wrong.

\footnotetext{
${ }^{16}$ We take out DMA fixed effects in specifications that use shop fixed effects, since they are collinear with shop fixed effects.
} 


\section{$5.2 \quad$ Price knowledge and gender}

In addition to randomly assigning conditions to repair shops, we also randomized whether calls made to a given shop were made by male or female call center agents. In this section we report the results of analyzing the effect of different conditions by the gender of the caller. This allows as to investigate the empirical predictions depicted in Figure 2.

Figure 4 on page 44 shows the distribution of prices by condition and gender. Visual inspection of the means displayed in the figure suggests that men are quoted close to the same average price as women in both the informed and misinformed conditions, but that women are quoted a higher average price than men in the uninformed condition. In order to assess the size and statistical significance of these comparisons, we add interaction effects between condition and gender to the specification in Equation 7, thereby obtaining Equation 8.

$$
\text { PriceQuote }_{i j t}=\beta_{0}+\beta_{\mathbf{1}} \text { Condition }_{\mathbf{i}} \times \text { Gender }_{\mathbf{j}}+\beta_{\mathbf{2}} \text { Controls }_{\mathbf{i j t}}+\nu_{i j t}
$$

Gender $_{j}$ is an indicator variable for the gender of agents making calls to shop $j .{ }^{17}$

In Table 3 we report the results from estimating Equation 8. In the table, the omitted category is the informed condition for male callers. Hence, all coefficients measure the effect of different conditions for male or female callers relative to the informed condition for male callers. As in Table 2, the first four columns of Table 3 differ in the controls they use: column 1 reports on the results of Equation 8 without controls and column 4 reports on the estimation with full controls. ${ }^{18}$ Results vary little as controls are added. ${ }^{19}$ Therefore we focus on column 1.

We find that repair shops quote men and women the same price on average in the informed condition, as indicated by the statistically insignificant coefficient estimate of -0.45 for "Informed, Women." Similarly, men and women are quoted the same price on average in the misinformed condition, as indicated by the statistically indistinguishable coefficient estimates of 35 for "Misinformed, Women" and 33 for "Misinformed, Men." 20

\footnotetext{
${ }^{17}$ An individual shop received calls from a single gender of agents. In some cases, the calls were made by different agents of the same gender; in others both calls were made by the same agent.

${ }^{18}$ Note that one consequence of our decision to use a single gender for all calls made to an individual shop is that we cannot identify gender effects on price quotes in a specification that also uses shop fixed effects. This is because results estimated using shop fixed effects are identified by within-shop variation, and there is no within-shop variation in caller gender, only in condition. We can still estimate the differences between conditions using shop fixed effects, but the estimated effects should be interpreted as the average within-shop differences between conditions for male callers (for shops that received calls from male agents) and for female callers (for shops that received calls from female agents). In Table A-1 in the appendix we report these results separately for the subsample of shops that received calls from male agents and for the subsample of shops that received calls from female agents.

${ }^{19}$ To verify that results are not sensitive to second call, we also estimate the models in columns $1-3$ for first calls only. The results of this estimation are reported in Table A-2 in the appendix.

${ }^{20} \mathrm{An}$ F-test of the hypothesis that these two coefficients are equal fails to reject equality with a p-value of 0.95 .
} 
However, our prior finding that callers in the uninformed condition were quoted the same price on average as callers in the informed condition no longer holds when we analyze the effect by gender. Specifically, female callers are quoted prices that are $\$ 13.3$ higher $(p=0.01)$ in the uninformed condition than in the informed condition. ${ }^{21}$ In contrast, we estimate that male callers are quoted prices that are $\$ 9.9$ lower $(p=0.07)$ when they do not mention a benchmark price than when they communicate a market-based benchmark price. (Note, however, that the estimate of the differences for males between the uninformed condition and the informed condition is of borderline statistical significance across the four columns.) Taken together, these results imply that female callers are quoted on average almost $\$ 23$ more than male callers when they don't communicate a benchmark price to the repair shop.

We observe a a surprising pattern. When callers reveal a benchmark price to shops, they are treated the same whether male or female. This is true whether the benchmark price reveals the caller to be informed (benchmark price of $\$ 365$ ) or misinformed (benchmark price of $\$ 510$ ). However, when shops are given no direct indication of a caller's price information (uninformed condition), they appear to draw inferences from the caller's gender that lead them to offer male and female callers different initial price quotes. Female callers in the uninformed condition are offered prices that are higher than male callers in the same condition, and higher than is offered to female callers in the informed condition. Male callers who are uninformed are offered lower prices than female callers in the same condition and lower than the prices offered to informed male callers. In short, shops appear to respond to the best available information they have about consumers' price knowledge, drawing inferences from gender if that is all they have to go on, but disregarding the gender signal if they are provided more direct information about consumers' price knowledge. This suggests that contrary to our hypotheses, when shops receive an informative signal about reservation prices, they fully update their beliefs about consumer's reservation prices and disregard the gender signal. Further, the signal of being uninformed seems to have one interpretation when the caller is a woman (higher than average reservation price) and another when it is a man (average or lower than average reservation price).

Linking back to our theory model in Section 3, these results differ in some surprising ways from our initial predictions in Figure 2. We summarize these differences in Figure 5, where empirical results that differ from our initial predictions are highlighted in italic type. (Figure 5 is based on the results reported in Table 3, column 1). First, we predicted that within an information condition, women would be quoted higher prices than men. This is the result we observe for the uninformed

\footnotetext{
${ }^{21}$ An estimate of $\$ 13.3$ for this effect is obtained from the regression coefficients by subtracting the coefficient of -0.45 for "Informed, Women" from the coefficient of 12.9 for "Uninformed, Women." The p-value is derived from an F-test of the equality of the two coefficients.
} 
condition, which is consistent the notion from our theory model that repair shops believe that a woman is more likely to be a high reservation price type consumer than a man is; in other words, that $\alpha_{\text {Uninformed }}^{W}>\alpha_{\text {Uninformed }}^{M}$. However, in the other information conditions, our results suggests that contrary to the theoretical prediction, $\alpha_{\text {Informed }}^{W}=\alpha_{\text {Informed }}^{M}$, and that $\alpha_{\text {Misinformed }}^{W}=$ $\alpha_{\text {Misinformed }}^{M}$. In addition, we predicted that in both the misinformed and the uninformed conditions, callers of either gender would be quoted higher prices than in the informed condition. This result holds for the misinformed condition, suggesting that repair shops believe that callers who cite a higher benchmark price is likely to be a higher reservation price type consumers $\left(\alpha_{\text {Misinformed }}^{W}>\right.$ $\alpha_{\text {Informed }}^{W}$ and $\alpha_{\text {Misinformed }}^{M}>\alpha_{\text {Informed }}^{M}$ ). However, this is not the case for the uninformed condition. In particular, while the findings suggest that women in the uninformed condition are believed to be more likely to have higher reservation prices than women in the informed condition $\left(\alpha_{\text {Uninformed }}^{W}>\right.$ $\alpha_{\text {Informed }}^{W}$, the findings for men suggest that shops may believe that a man who cites the market price as a benchmark price is more likely to have high reservation prices than a man who does not cite a benchmark price at all $\alpha_{\text {Informed }}^{M} \geq \alpha_{\text {Uninformed }}^{M}$.

\subsection{Using benchmark prices to ask for price concessions}

So far we have investigated how mentioning a benchmark price changes the initial price quote provided by repair shops. We have interpreted the estimated results as evidence that repair shops adjust their initial price quotes according to how well-informed a shop thinks a caller is, conveyed in part by the benchmark price a caller communicates. While signaling price knowledge is one role that a benchmark price can play in such an interaction, it can also play a second role - as a reference point in bargaining with the repair shop. To investigate the role of benchmark prices as a bargaining reference we instructed our field experiment callers to determine immediately after obtaining the initial price quote whether the initial price quote exceeded the benchmark price. If so, callers asked shops whether they would match the benchmark price. In the informed and misinformed conditions we instructed them to say, "So, I have a question. Would you match the price of $\$ 365$ ( $\$ 510)$ that the website AutoMD said it should cost in this area?" In the uninformed condition we had callers request a price concession if the initial price quote exceeded $\$ 365$ : "So, I have a question, I just visited the website AutoMD.com, and for this area they say the cost should be $\$ 365$. Would you match this price?" We then had the agents record whether the repair shop revised its price quote. We refer to the difference between the initial price quote and the revised price quote as the PriceConcession. ${ }^{22}$

\footnotetext{
${ }^{22}$ All subsequent results are estimated only in the subset of the sample where the initial price offer was greater than either the benchmark price of either $\$ 365$ or $\$ 510$. (Asking the repair shop to match the benchmark price when the initial price quote was actually below the benchmark price would have been nonsensical.) Thus, our results
} 
Overall, we find that shops agree to some form of price concession $26 \%$ of the time, meaning that $74 \%$ of caller requests to modify the price were not successful. How frequently shops agree to make a price concession varies between the information conditions. As shown in Table 4, shops are much more likely to modify the price when asked to match $\$ 510$ than when asked to match $\$ 365$ $\left(p\right.$-value $<0.01$ in a $\chi^{2}$ test $) .{ }^{23}$

One might think that this is because lowering the price to $\$ 510$ requires less of a concession than lowering the price to $\$ 365$. Consistent with this, the average amount by which the initial price quote exceeds the benchmark price is lower by $\$ 19$ in the misinformed condition than in the other conditions. To see whether shops are more likely to modify the price when the request is to match $\$ 510$ rather than $\$ 365$, even when controlling for the magnitude of the requested concession, we estimate the following specification:

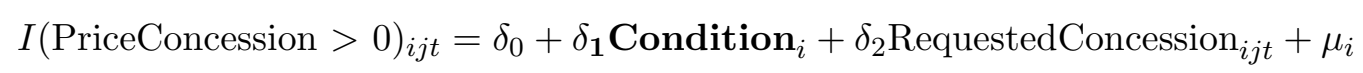

Condition contains indicator variables for the different price knowledge conditions. RequestedConcession controls for the difference between the initial price quote and benchmark price ( $\$ 365$ or $\$ 510)$. In column 1 of Table 5 we control for this difference linearly. In column 2 we control for this difference non-parametrically by including indicator variables for deciles of the difference between the initial price quote and requested price. The results show that shops remain significantly more likely to agree to a price concession (by 16 percentage points) in the misinformed condition than in other conditions, even when holding constant the magnitude of the requested concession.

Next, we explore whether men and women are equally likely to obtain price concessions when they bargain. We estimate this in column 3 of Table 5 by replacing the condition indicators in Equation 9 with a gender indicator. The results show that women are significantly more likely than men (by 11 percentage points) to obtain price concessions from repair shops. Note that because we control directly for the size of the requested concession, this result is not an artifact of women receiving higher initial price quotes in the uninformed condition.

Finally, we would like to know whether the likelihood of obtaining a price concession depends on the interaction of gender and condition. In column 4 of Table 5 we add condition and gender interaction effects to the specification in equation 9 . We find that repair shops are more likely to

should be interpreted as the effect of gender on the size of a concession when the request is to match an announced benchmark price. In other words, it is the average treatment effect on a particular treatment group, defined by the kind of concession we had agents ask for. If we had had another rule for the concession the agents were to ask for-for example, "Ask for a price $\$ 30$ lower, whatever the initial price quote" - then we could estimate the effect of concession requests in the entire sample.

${ }^{23}$ Formally, the test was of whether the probability of making a price concession in the misinformed condition versus the probability of making a price concession in the informed and uninformed conditions pooled. 
give a price concession to a female caller than to a male caller, irrespective of condition (although the gender difference for the uninformed condition is only marginally significant at $p=0.052$ ). However, the gender difference is largest in the misinformed condition (even though we control for the size of the requested concession).

If we compare the results in column 4 across conditions for a single gender rather than across gender for a single condition, we see that men are statistically equally likely to obtain a price concession in the three conditions, controlling for the size of the requested concession. For women, however, the probability of obtaining a concession is highest in the misinformed condition, even controlling for the size of the requested concession. Most interesting, however, is the result that women are more likely to obtain a concession in the informed condition than in the uninformed condition $(p$-value $=0.09)$, even though in both cases the caller is asking the shop to match a price of $\$ 365$. This result suggests that for women, there is a double benefit to revealing they are informed about prices: doing so not only leads on average to a lower initial price quote (Table 3), it also leads to a higher probability of obtaining a concession, should the initial quote exceed the market-based benchmark price. Together these results suggest that a woman in this context has a distinct advantage in revealing good price knowledge early on.

One might worry that the results for the uninformed condition could be affected by selection for the following reason. Agents only asked for a price concession if the original price quote exceeded $\$ 365$ (in the uninformed and informed condition) or $\$ 510$ (in the misinformed condition). However, in the uninformed condition, women receive higher initial price quotes than men do, which means that women are asking for price concessions at a greater number of shops than men are. One could think of there being a set of shops where a woman would be quoted a price above $\$ 365$ and therefore ask for a concession, but where a man would be quoted a price below $\$ 365$ and therefore would not ask for a concession. The selection question is whether this set of shops is more likely or less likely to offer price concessions irrespective of the gender of the agent than the shops which would quote both men and women prices above $\$ 365$. If the shops who quote women higher prices are also more or less likely to agree to concessions than other shops, it would bias our estimate of the difference between men and women in the probability of receiving a price concession. ${ }^{24}$ There should be no selection effect in the informed and misinformed conditions since men and women are quoted the same prices on average. This means that, since agents are assigned randomly to shops, there should not be systematic differences in the shops where women are asking for price concessions and where men are asking for price concessions. ${ }^{25}$

\footnotetext{
${ }^{24}$ We thank Stephan Seiler and seminar participants at Stanford GSB for pointing this possibility out to us.

${ }^{25}$ Women and men are also offered the same prices on average if we restrict the sample to calls in which the original price quote was at least $\$ 365$ in the informed condition or $\$ 510$ in the misinformed condition.
} 
It turns out that our empirical results are inconsistent with this type of selection for the following reasons. First, suppose that the set of shops at which only a woman would be quoted an initial price above $\$ 365$ offer concessions more frequently, irrespective of the gender of the caller, than the shops at which both men and women would be offered prices above $\$ 365$. If this were the case, then in column 4 of Table 5 , the estimated coefficient for "Uninformed, Women" should be higher than the coefficient on "Informed, Women" and "Misinformed, Women" since the uninformed condition would contain a positive selection bias that the other two coefficients would not. (Women would receive concessions more frequently relative to men in the uninformed condition than in the other two conditions, because of the sample of shops in the uninformed condition at which only women are asking for concessions.) Instead, the reverse is true. The female indicator variable is lower in the uninformed condition than in the other two conditions. Now suppose that the reverse is true; that the set of shops at which only women would be quoted a price above $\$ 365$ offers concessions less frequently, irrespective of the caller's gender, than shops that would quote prices above $\$ 365$ to both men and women. If this is the case, then the coefficient on "Uninformed, Women" should be negative. (Women in the uninformed condition should receive concessions less often on average than men because some of the shops at which women are asking for concessions grant them less frequently.) This is the opposite of what we estimate. Our estimates are consistent with neither direction of the possible selection bias. ${ }^{26}$

Having established that women are significantly more likely than men to obtain price concessions from repair shops, we analyze next whether the magnitude of the price concession differs by condition and gender. We estimate the following Tobit specification using data only from calls where agents requested a price concession:

$$
\text { PriceConcession }_{i j t}=\gamma_{0}+\gamma_{\mathbf{1}} \text { Condition }_{i} \times \text { Gender }_{j}+\gamma_{2} \text { RequestedConcession }_{i j t}+\nu_{i j t}
$$

where PriceConcession is truncated from below at zero and Condition $\times$ Gender contains interaction variables for gender and condition. The results are reported in column 5 of Table 5 . According to the estimates, when men request a concession, the size of the concession granted does not vary across conditions in a statistically significant way. Women obtain larger price concessions than men in each of the conditions; furthermore, for women, the size of the concession varies across conditions. Women in the uninformed condition who requested a concession obtained a $\$ 22$ higher concession than uninformed men (marginally significant). Women in the informed condition obtained a $\$ 35$ higher concession than men. Finally, women in the misinformed condition obtained

\footnotetext{
${ }^{26}$ The negative selection bias could make the "Uninformed, Women" coefficient smaller than it otherwise would be, but this can't be the dominant determinant of this coefficient, since the coefficient is positive rather than negative.
} 
a $\$ 54$ higher price concession than men. Note that the larger average price concessions women obtain are due to the higher likelihood of women to obtain a concession in the first place. In particular, if we estimate equation 10 in the subsample of observations where the caller obtains a concession (i.e. conditional on PriceConcession $>0$ ), the size of the concession varies neither by gender nor by price knowledge condition. These results are reported in the appendix in Table A-3.

In summary, we have shown that the likelihood of obtaining a price concession as well as the size of the concession depends on both the information condition and how large a concession is requested. We have also shown that women are significantly more likely than men to obtain price concessions from repair shops. ${ }^{27}$ The design of our experiment does not enable us to do more than speculate about why women are more likely to obtain a price match than men are. We have evidence that most of the repair shop employees to whom callers spoke were male. ${ }^{28}$ It may be that men are more likely because of social or cultural conditioning to respond positively to requests made by women. Research by Babcock, Laschever, Gelfand, and Small (2003) indicates that women are less likely to ask for things such as raises (or perhaps price concessions) in negotiations. Further, Leibbrandt and List (2015) demonstrate that women are likely to negotiate in environments where negotiability is explicit, but shy away from negotiations when they do not perceive a situation as a negotiation opportunity. Women may not consider asking for a quote or shopping for prices as a negotiation opportunity, thereby further reducing the likelihood that a woman would ask for a price reduction. If these findings are true on average for women in the repair shop context, repair shops may interpret a woman asking for a concession as being a signal that she is more dissatisfied with the price offer she has received (because it has actually prompted her to take the relatively uncommon step of asking for a price match) than a man is when he asks for a concession.

\subsection{Downward-biased benchmark prices}

After we concluded most of the data collection for the first experiment, we decided to investigate the effect of a "downward-biased" condition, for which we chose a benchmark price of $\$ 310$. We wanted to compare the price quotes that callers obtained in the downward-biased condition to price quotes obtained in other conditions. However, the data gathered on various conditions in experiment 1 could not be used to construct an experimentally valid counterfactual for the downward-biased condition in experiment 2 for two reasons. First, we started the second experiment in the 12 th week

\footnotetext{
${ }^{27}$ All these results are robust to inclusion of week, DMA, and call order controls (see Table A-4 on page Web Appendix-7 in the appendix).

${ }^{28}$ We did not ask our callers to record the gender of the repair shop employee to whom they spoke. Nonetheless, in 915 cases agents recorded the name of the employee they spoke to of their own accord. In this sample, 814 of the names were male, 75 were female, and the rest could be either. Due to the small sample, we cannot test the hypothesis that male repair shop employees are more likely than female employees to make concessions to female callers.
} 
of the first experiment. The two experiments ran concurrently for only three weeks. In addition, during these three weeks we were conducting only second calls to repair shops in experiment 1 , whereas we were calling repair shops in experiment 2 for the first time. (Because experiment 2 was initiated near the end of our experimental period, we did not have enough time to call the shops in experiment 2 for the first time, wait a few weeks, and then follow-up with a second call under another condition. As a result, shops in experiment 2 were called only once, with a single experimental condition.) Second, for experiment 1 we called all shops that were located in DMAs with 150 or more repair shops. These DMAs largely correspond to the most populous DMAs in the nation. As a result, for experiment 2 we had to call repair shops in smaller DMAs, specifically shops in DMAs with 70 to 149 repair shops.

Because we knew that we would step outside the experimental paradigm if we pooled the data from both experiments, in experiment 2 we replicated the uninformed condition along with the downward-biased condition. This way we had one experimentally valid counterfactual for the downward-biased condition.

Citing a below market price as a benchmark price may have two different interpretations. It could mean that the consumer is a strategic consumer who knows the average market price and is trying to signal to the seller that he or she has a low reservation price. If this were the case, the reservation price would be lower than the reservation price in the uninformed condition and thus $\alpha_{\text {Uninformed }}>\alpha_{\text {Downward-Biased }}$ for both men or women. On the other hand, it could be that the consumer is misinformed about the market prices. In that case, it is not clear what the relation between $\alpha_{\text {Uninformed }}$ and $\alpha_{\text {Downward-Biased }}$ would be.

The initial price quote results of experiment 2 are reported in Table 6 . In column 1 we analyze whether mentioning a downward-biased benchmark price yields a lower initial price quote than not mentioning a benchmark price. Column 2 repeats the analysis while controlling for week and DMA fixed effects. In these two columns our point estimates indicate that average price quotes are lower in the downward-biased condition, by $\$ 7.4$ and $\$ 8.4$, respectively, but these differences are not statistically different from zero ( $p=0.12$ in column 1 and $p=0.11$ in column 2). Moreover, when we investigate interactions between gender and the two information conditions in column 3 of Table 6 , we find no statistically significant effects.

We can also investigate the likelihood of obtaining a price concession in experiment 2 . Table 7 shows that callers are less likely to obtain a price concession when they ask the shop to match a price of $\$ 310$ than when they ask the shop to match a price of $\$ 365$ ( $p$-value $<0.01$ in a $\chi^{2}$ test). ${ }^{29}$

Similar to what we found in subsection 5.3, this difference seems to be driven not by the

\footnotetext{
${ }^{29}$ For consistency with experiment 1 we instructed callers to request $\$ 365$ in the uninformed condition.
} 
condition directly, but instead by the size of the requested concession. In column 1 of Table 8, we reestimate Equation 9 using data from experiment 2. We find no statistically significant difference between conditions in the probability of obtaining a price concession, once we control for the size of the requested concession. We also find that women are (statistically weakly) more likely to obtain a price concession than men in the uninformed condition, but we find no difference across genders in the downward-biased condition, as shown in column 2 of Table 8. This is consistent with our prior finding that the female effect seemed to be smaller for lower requested prices (column 4 of Table 5). Finally, as shown in column 3, the magnitude of price concessions vary neither by condition nor gender.

\section{Robustness}

In this section we explore the robustness of our findings. We began by investigating agents' adherence to our experimental protocol. To make sure that calls were conducted in the way we intended, we put several safeguards in place. First, we regularly communicated with the call center supervisor to discuss the progress of the experiment and react to unexpected issues. Second, the call center supervisor held weekly meetings with agents where she assigned them spreadsheets that we created, which contained each agent's randomly assigned shops and randomly assigned conditions for the week. During those meetings she communicated any instructions we wanted implemented. Third, to make sure that agents were following the correct script for each experimental condition, we printed on each script a 3 -digit "script code" (e.g., "181"). We changed the script code whenever we changed the wording of the script, or updated instructions on how to fill out the spreadsheet. ${ }^{30}$ Agents were required to manually enter these codes in a spreadsheet column at the end of each call. Fourth, we monitored comments made by agents in the spreadsheet in which they noted anything that struck them as noteworthy during the call. Analyzing these comments serves the purpose of both recording shop behavior that we had not anticipated as well as monitoring agent behavior by observing what agents felt was necessary to point out.

In the web appendix we investigate how our estimated results change if we make data corrections to account for inconsistent and/or problematic behavior by agents. The first problem we identified is that out of the 6,544 price quotes obtained during the course of the two experiments, in 249 instances $(3.8 \%)$ the agent had recorded the incorrect script code. We reran the main regressions after dropping all 249 quotes with incorrect script codes (see subsection 1 of the robustness section

\footnotetext{
${ }^{30}$ This occurred when we updated the wording of scripts between the pre-test and the beginning of the experiment, when we updated instructions on how to fill out the spreadsheet before week 3 and again week 5 , and when we introduced experiment 2 .
} 
in the web appendix). While the point estimates changed slightly, none of our conclusions were affected by dropping quotes with incorrect script codes.

Second, we reviewed the comments entered by agents when they considered something out of the ordinary. We noticed that for $13 \%$ of price quotes, shops asked agents to call back before they gave a price quote. This reflects situations in which the shop could not pull together a price quote while staying on the phone, perhaps because of other demands on the shop employee's attention. For an additional $1 \%$ of the quotes in our data, agents were asked to call back after they had obtained the initial price quote but before they were given a revised price quote in response to their request to match one of the benchmark prices. Both of these requests for a call-back are potentially problematic because we don't know whether our experimental manipulation had the same effect on quotes that were assembled once the agent was off the phone. As a result, we reestimate our main specifications after eliminating all quotes for which an agent noted that the shop requested a call-back before the quote was obtained (see subsection 2 of the robustness section in the web appendix). None of our conclusions changed.

Third, we noticed that for $3.4 \%$ of price quotes, agents noted that the shop had referred to the price quote it gave as a "rough estimate." To ensure that our findings are not driven by these observations, we reestimate our main specifications after eliminating all quotes that were classified as "rough estimates" (see subsection 3 of the robustness section in the web appendix). The conclusions from experiment 1 do not change. However, there are two results from experiment 2 that change when we drop these observations. First, the experiment 2 result that women are more likely to obtain a price concession in the uninformed condition falls in magnitude and is no longer statistically significant even at the $10 \%$ confidence level. Second, the experiment 2 result that women obtain larger price concession than men is only marginally statistically different than zero for the misinformed condition and no longer significant for the other conditions.

Fourth, the DMA fixed effects estimated in Table 2 suggest that there is heterogeneity in the average prices of repairs across DMAs. If this is the case, then the benchmark price of $\$ 365$ that we have callers cite in the informed condition may be above the market price in some DMAs and below the market price in others. As a result, one might worry that the effect of the informed condition would not be the same in high-price DMAs and low-price DMAs. ${ }^{31}$ In order to investigate this, in unreported results we use pre-experiment data from AutoMD on prices across DMAs for a variety of Toyota repairs to divide DMAs into quintiles according to how expensive Toyota repairs are. We then re-estimate our main specification interacting indicator variables for these DMA quintiles with the informed and uninformed condition indicators. We do not find any evidence that the

\footnotetext{
${ }^{31}$ We thank an anonymous referee for suggesting this point.
} 
results vary across DMA quintiles.

Finally, we noticed an inconsistency over time in how agents applied scripts and specifically in whether they insisted on including particular aspects of the radiator repair in the recorded price quotes. We discuss this concern extensively in subsection 4 of the robustness section in the web appendix. We find that our main findings are largely robust to three different approaches for correcting for these execution issues, with two exceptions, as summarized below.

The first exception is in one of the initial price quote results. In the results reported in Sections 5.1 and 5.2 we find, across all our specifications, that the price quotes in the misinformed condition are higher than in the other conditions by about $\$ 24-\$ 35$. In addition, we consistently find that women in the uninformed condition are quoted higher prices than men in that condition, and than men and women in the informed condition. These results continue to hold if we correct for execution issues. In Section 5.2 we also found some evidence that men in the uninformed condition were quoted lower prices than men in the informed condition. However, this result is not statistically robust to correcting for execution issues, although the direction of the results remains throughout most of the specifications. The second exception is that in one of the adjusted price concession specifications, women in the uninformed condition are are no longer more likely to obtain price concessions than men.

\section{Concluding remarks}

In this paper we have presented the results of an experiment designed to measure the differences in the price quotes sellers offer to customers who present themselves as being uninformed, informed, or misinformed about price. Our experiment also varies the gender of buyers, in order to understand whether the effects of information differ across genders. By scripting the buyer's side of the negotiation, this experimental design focuses specifically on the seller's response to buyers who are differentially informed.

In our results we find that callers who ask for repair shop quotes after announcing that they have no idea what the repair should cost are quoted the same prices on average as callers who announce first that they have learned that the repair should cost an amount that is approximately the market average. The overall averages, however, mask differences between genders: female callers who say they are uninformed about prices are quoted prices about $\$ 20$ higher than male callers who present themselves the same way. However, there is no difference between genders for callers who present themselves as correctly informed about prices. There is also no difference between genders for callers who announce that they have learned that the repair should cost an amount that is much higher than the actual market price. 
We note that one way we could observe such an outcome would be if repair shops believe that women are on average less well informed about prices than men, and price accordingly when callers present no direct information about how informed they are. In order to explain the rest of our observed results, however, we must conclude that when presented with direct information of how well informed a caller is, the repair shops price according to that information and no longer find gender a useful basis on which to price discriminate.

In our experiment, we also directed the callers to ask for price concessions if their initial quote exceeded the benchmark price in the relevant information condition. Our results show that shops are more willing to agree to a price concession for a female than for a male caller. In addition, shops were more likely to agree to a price concession for a female caller if she first presented herself as correctly informed than if she first presented herself as uninformed, even though the price the shops were being asked to match was the same in those two conditions. These results together suggest that there is a double benefit to women to presenting themselves as correctly informed in these negotiations: first, they obtain lower initial price quotes on average, and second, if they obtain a high initial price quote, they are more likely to be able to negotiate a price concession. 


\section{References}

Anderson, E., And D. Simester (2008): "Price Cues and Customer Price Knowledge," in Handbook of Pricing Research in Marketing, ed. by V. Rao, pp. 150-168. Elgar Publishing Ltd., Northampton, MA.

Anderson, S. P., And A. De Palma (2005): "Price Dispersion and Consumer Reservation Prices," Journal of Economics and Management Strategy, 14(1), 61-91.

Ayres, I., And P. Siegelman (1995): "Race and Gender Discrimination in Bargaining for a New Car," American Economic Review, 85(3), 304-321.

Babcock, L., S. Laschever, M. Gelfand, and D. Small (2003): "Nice Girls Don’t Ask," Harvard Business Review, 81(10), 14-16.

Baye, M. R., J. Morgan, and P. Scholten (2006): "Information, Search, and Price Dispersion," Discussion paper, IDEAS.

Bertrand, M., and S. Mullainathan (2004): "Are Emily and Greg More Employable Than Lakisha and Jamal? A Field Experiment on Labor Market Discrimination," American Economic Review, 94(4), 991.

Biswas, A., E. J. Wilson, and J. W. Licata (1993): "Reference Pricing Studies in Marketing," Journal of Business Research, 27(3), 239-256.

Brown, J. R., And A. Goolsbee (2002): "Does the Internet Make Markets More Competitive? Evidence from the Life Insurance Industry," Journal of Political Economy, 110(5), 481-507.

Carlson, J. A., and P. McAfee (1983): "Discrete Equilibrium Price Dispersion," Journal of Political Economy, 91(3), 480-493.

Castillo, M., R. Petrie, M. Torero, and L. Vesterlund (2013): "Gender Differences in Bargaining Outcomes: A Field Experiment on Discrimination," Journal of Public Economics, 99, 35-48.

Galinsky, A., And T. Mussweiler (2001): "First Offers and Anchors: The Role of PerspectiveTaking and Negotiator Effects," Journal of Personality and Social Psychology, 81(4), 657-669.

Gneezy, U., J. List, And M. K. Price (2012): "Toward an Understanding of Why People Discriminate: Evidence from a Series of Natural Field Experiments," Working paper 17855, National Bureau of Economic Research.

Kalyanaram, G., and R. Winer (1995): "Empirical Generalizations from Reference Price Research," Marketing Science, 14(3), G161-G169.

Leibbrandt, A., And J. List (2015): "Do Women Avoid Salary Negotiations? Evidence from a Large Scale Natural Field Experiment," Management Science, 61(9), 2016-2024.

Mazumdar, T., S. Raj, and I. Sinha (2005): "Reference Price Research: Review and Propositions," Journal of Marketing, 69(10), 84-102. 
Monroe, K. B., And A. Y. Lee (1999): "Remembering versus Knowing: Issues in Buyers' Processing of Price Information," Journal of the Academy of Marketing Science, 27(2), 207-225.

Moosmayer, D. C., B. Schuppar, and F. U. Siems (2012): "Reference Prices as Determinants of Business-to-Business Negotiation Outcomes: An Empirical Perspective from the Chemical Industry," Journal of Supply Chain Management, 48(1), 92-106.

Salop, S. (1977): "The Noisy Monopolist: Imperfect Information, Price Dispersion, and Price Discrimination," Review of Economic Studies, 44(3), 393-406.

SAlop, S., And J. Stiglitz (1977): "Bargains and Ripoffs: A Model of Monopolistically Competitive Price Dispersion," Review of Economic Studies, 44(3), 493-507.

Schneider, H. (2012): "Agency Problems and Reputation in Expert Services: Evidence from Auto Repair," Journal of Industrial Economics, 60(3), 406-433.

Sorensen, A. (2000): "Equilibrium Price Dispersion in Retail Markets for Prescription Drugs," Journal of Political Economy, 108(4), 833-850.

Stahl, D. O. (1989): "Oligopolistic Pricing with Sequential Consumer Search," American Economic Review, 79(4), 700-712.

(1996): "Oligopolistic Pricing with Heterogeneous Consumer Search," International Journal of Industrial Organization, 14, 243-268.

Stigler, G. J. (1961): "The Economics of Information," Journal of Political Economy, 69(3), $213-225$.

Tsay, C.-J., And M. Bazerman (2009): "A Decision-Making Perspective to Negotiation: A Review of the Past and a Look to the Future," Negotiation Journal, 25(4), 467-480.

Valley, K., S. Blount White, M. Neal, and M. Bazerman (1992): "Agents as Information Brokers: The Effects of Information Disclosure on Negotiated Outcomes," Organizational Behavior and Human Decision Processes, 51, 220-236.

Van Poucke, D., and M. Buelens (2002): "Predicting the Outcome of a Two-Party Price Negotiation: Contribution of Reservation Price," Journal of Economic Psychology, 23(1), 67-76. 


\section{Appendix}

In this appendix we show that $\phi_{\alpha}$, the derivative of the first order condition in equation 5 is positive. Showing this enables us to $\operatorname{sign} p_{\alpha}^{*}$ (from equation 6) as positive, which implies that the optimal price for a seller to quote is increasing in $\alpha$, the probability the seller assigns to the buyer being of the high reservation type. We begin by expressing $\phi_{\alpha}$ as:

$$
\phi_{\alpha}=f^{H}(p)\left\{\frac{1-F^{H}(p)}{f^{H}(p)}-(p-c)\right\}-f^{L}(p)\left\{\frac{1-F^{L}(p)}{f^{L}(p)}-(p-c)\right\} .
$$

In order to sign $\phi_{\alpha}$, we proceed in two steps. First, we make use of the assumption that $F^{H}$ hazard rate dominates $F^{L}$, meaning that $\frac{1-F^{H}(p)}{1-F^{L}(p)}$ is increasing in $p$. This implies that the derivative of $\frac{1-F_{H}(p)}{1-F_{L}(p)}$ with respect to $p$ is positive:

$$
\frac{\partial}{\partial p}\left[\frac{1-F_{H}(p)}{1-F_{L}(p)}\right]=\frac{-f_{H}(p) \cdot\left[1-F_{L}(p)\right]-\left[1-F_{H}(p)\right] \cdot\left[-f_{L}(p)\right]}{\left[1-F_{L}(p)\right]^{2}}>0
$$

Since the denominator is a squared term, it is positive. Hazard rate dominance therefore implies that the numerator of the expression in equation 12 is positive, namely that:

$$
-f_{H}(p) \cdot\left[1-F_{L}(p)\right]-\left[1-F_{H}(p)\right] \cdot\left[-f_{L}(p)\right]>0 .
$$

Since $f_{H}(p)$ and $f_{L}(p)$ are density functions, they are both positive, which means that we can rearrange terms in equation 13 , then divide both sides by $f_{H}(p)$ and $f_{L}(p)$ to obtain the following expression:

$$
\frac{1-F_{H}(p)}{f_{H}(p)}>\frac{1-F_{L}(p)}{f_{L}(p)} .
$$

The second step begins by noting that the first order condition in equation 5 can be written as

$$
\phi(p, \alpha)=\alpha f^{H}(p)\left\{\frac{1-F^{H}(p)}{f^{H}(p)}-(p-c)\right\}+(1-\alpha) f^{L}(p)\left\{\frac{1-F^{L}(p)}{f^{L}(p)}-(p-c)\right\}=0
$$

Because $\alpha, 1-\alpha$, and both density functions $f^{H}(p)$ and $f^{L}(p)$ are positive, the left hand side of this expression can equal zero only if the terms $\frac{1-F^{H}(p)}{f^{H}(p)}-(p-c)$ and $\frac{1-F^{L}(p)}{f^{L}(p)}-(p-c)$ are both equal to zero, or if one of the terms is positive and one of the terms is negative. The strict inequality in equation 14 tells us that the terms cannot both be equal to zero. Therefore, one of them must be greater than zero and the other less than zero, and furthermore that the " $\mathrm{H}$ " term is the one that must be positive and the " $L "$ term must be the one that is negative. If this is true, then it must also be the case that

$$
f^{H}(p)\left\{\frac{1-F^{H}(p)}{f^{H}(p)}-(p-c)\right\}>0>f^{L}(p)\left\{\frac{1-F^{L}(p)}{f^{L}(p)}-(p-c)\right\} .
$$

This tells us that the expression for $\phi_{\alpha}$ in equation 11 is a positive number minus a negative number and therefore positive overall, which means that $p^{*}(\alpha)$ is increasing in $\alpha$, or in other words that the optimal price for a seller to quote to a buyer of unknown type is increasing in the probability the seller places on the buyer being of the high reservation price type. 


\section{Tables}

Table 1: Experimental Conditions

\begin{tabular}{|l|l|l|l|l|}
\hline Variable & Uninformed & Informed & Misinformed & $\begin{array}{l}\text { Downward- } \\
\text { Biased }\end{array}$ \\
\hline Benchmark price mentioned at outset of & None & $\$ 365$ & $\$ 510$ & $\$ 310$ \\
call & & & \\
\hline Price used in request for price concession & $\$ 365$ & $\$ 365$ & $\$ 510$ & \\
\hline \begin{tabular}{l} 
Observations in experiment 1 \\
\hdashline Observations in experiment 2
\end{tabular} & 1,613 & 1,012 & 0 & 0 \\
\hline
\end{tabular}


Table 2: Effects of information condition

\begin{tabular}{|c|c|c|c|c|c|}
\hline Dependent Variable & Price Quote & $\begin{array}{c}(2) \\
\text { Price Quote }\end{array}$ & Price Quote & $\begin{array}{c}\text { (4) } \\
\text { Price Quote }\end{array}$ & $\begin{array}{c}5) \\
\text { Price Quote }\end{array}$ \\
\hline Uninformed & $\begin{array}{l}1.9 \\
(3.8)\end{array}$ & $\begin{array}{c}2.1 \\
(4.1)\end{array}$ & $\begin{array}{l}2.7 \\
(4)\end{array}$ & $\begin{array}{l}2.5 \\
(4)\end{array}$ & $\begin{array}{l}-.068 \\
(3.3)\end{array}$ \\
\hline $\bar{M} \overline{i s i n f o r m e d ~}^{-}$ & $\begin{array}{l}34 * * \cdots \\
(38)\end{array}$ & $35^{* *}$ & $\begin{array}{l}- \\
35 * *^{-} \\
(41)\end{array}$ & $35^{* *^{-}}$ & $24^{* *}$ \\
\hline$\overline{\text { Weè }} \bar{L}^{-\cdots}$ & & $\begin{array}{c}-1.1 \\
(18)\end{array}$ & $\begin{array}{r}-\overline{3} .7 \\
(17)\end{array}$ & $\begin{array}{l}-3.8- \\
(17)\end{array}$ & $-\overline{4} 5^{*-}$ \\
\hline Weēk $3^{--}$ & & $\begin{array}{ll}-3 \\
-3\end{array}$ & $\begin{array}{ll}-1 \\
-3\end{array}-2.6$ & -2.5 & -14 \\
\hline Weèk ${ }^{-}{ }^{--}$ & & $\begin{array}{l}-3.8 \\
(17)\end{array}$ & $\begin{array}{r}-720 \\
-7.7 \\
(16)\end{array}$ & $(16)$ & $\begin{array}{l}-25) \\
-36 \\
(23)\end{array}$ \\
\hline Weék $5^{-}$ & & $\begin{array}{l}-8.6 \\
(17)\end{array}$ & $\begin{array}{l}-12 \\
(16)\end{array}$ & $\begin{array}{l}-13 \\
(16)\end{array}$ & $\begin{array}{c}-39+ \\
(22)\end{array}$ \\
\hline Week $^{-} \overline{6}^{--}$ & & -1.5 & -4.8 & -7.2 & $-46+$ \\
\hline Weè ${ }^{-} 7^{-}$ & & $\begin{array}{l}-9.4 \\
(17)\end{array}$ & $\begin{array}{l}-13 \\
(16)\end{array}$ & $\begin{array}{l}-17 \\
(17)\end{array}$ & $\begin{array}{c}-44+- \\
(25)\end{array}$ \\
\hline Weēk ${ }^{-}$ & & -7.2 & $\begin{array}{l}-12 \\
(16)\end{array}$ & -23 & $\begin{array}{c}-51- \\
-54)\end{array}$ \\
\hline Weèk ${ }^{-} 9^{-}$ & & $(19)$ & $\begin{array}{l}14 \\
(18)\end{array}$ & $\begin{array}{l}4.5 \\
(18)\end{array}$ & $\begin{array}{l}-46- \\
(32)\end{array}$ \\
\hline Weēk $^{-} 10^{-}$ & & $(19)$ & $\begin{array}{l}9.1 \\
(19)\end{array}$ & $\begin{array}{l}-4.4 \\
(19)\end{array}$ & $\begin{array}{c}-6 \overline{6}+ \\
-(37)\end{array}$ \\
\hline Weēk $11^{-}$ & & $\begin{array}{l}2.3 \\
(17)\end{array}$ & $\begin{array}{l}-1.9 \\
(17)\end{array}$ & $\begin{array}{l}-15 \\
(18)\end{array}$ & $\begin{array}{l}-60+ \\
(34)\end{array}$ \\
\hline Wee- ${ }^{-} 14^{-}$ & & -9.9 & -14 & -28 & $-67+$ \\
\hline Weèk $\overline{1} \overline{1}$ & & & -25 & $-38^{*}$ & $-73^{*-}$ \\
\hline Weèk ${ }^{-} \overline{1} \overline{6}^{-}$ & & -1.3 & -8.3 & -22 & $-53^{-}$ \\
\hline Boston (Manchester & & & $15+$ & $16+$ & (1) \\
\hline Charrōtète- & & & 2.8 & 2.8 & \\
\hline Chicago & & & $29^{*}$ & $29^{*}{ }^{*}-$ & \\
\hline Cleveland-Ākron (Canton) & & & $32^{*}$ & $33^{*}$ & \\
\hline Dāllās-Ft.' Worth̄ & & & -7.8 & $\begin{array}{l}-144 \\
-7.3 \\
(10)\end{array}$ & \\
\hline Denver & & & $2 \overline{4}^{* *}$ & $2 \overline{4}^{* *}$ & \\
\hline Détroit & & & $\begin{array}{l}9.4) \\
1.9\end{array}$ & $\begin{array}{l}(9.3) \\
1.8\end{array}$ & \\
\hline Iñaianāpōiés - - & & & 18 & -18 & \\
\hline Los Ángè-"-- & & & $\begin{array}{ll}-1 \\
-14+\end{array}$ & $-14^{*}$ & \\
\hline Míāìi-Fét. LāūdēerdāIe ${ }^{-}$ & & & 2.8 & 3 & \\
\hline Néw York & & & $(7.8)$ & $\begin{array}{l}-5.4- \\
-7.8\end{array}$ & \\
\hline Orlando-Dàytonà Bch-Mèlbrn & & & $\left(9.4^{-1}\right.$ & $\begin{array}{l}8.1 \\
(9.6)\end{array}$ & \\
\hline Philàdèlphia & & & $55^{* 34}$ & $56^{* 3-}$ & \\
\hline Phoenix (Prescotét $)^{-\cdots}$ & & & 5.6 & 5.4 & \\
\hline Pörtāna, Or ${ }^{--}$ & & & (g) & 5.9 & \\
\hline Sacramnto-Stkton-Móésto & & & 11) & $(172$ & \\
\hline Sàlt Lāke Cíty & & & -8.5 & $\begin{array}{l}-(11) \\
-8.4 \\
(0.9)\end{array}$ & \\
\hline San Francisco-Oak-San Jose & & & $30^{\text {*** }}$ & $30^{* *}$ & \\
\hline Seatte-Tacoma & & & $29^{* *}$ & $29^{* *}$ & \\
\hline Tampa-St. Pété (Sarasota) & & & 4.4 & 4.4 & \\
\hline 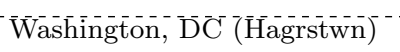 & & & $65^{*}$ & $65^{* * 3}$ & \\
\hline Second Cāll ${ }^{-\ldots}$ & & & & $13^{*}$ & $19^{-}$ \\
\hline Shop Fixed Effect & & & & & \\
\hline Constant & $\begin{array}{c}3 \overline{9} \overline{3}^{* *} \\
(2.7)\end{array}$ & $\begin{array}{c}3 \overline{9} \overline{6}^{* *} \\
(17)\end{array}$ & $\begin{array}{l}388^{* *} \\
(17)\end{array}$ & $\begin{array}{c}388^{* *} \\
(17)\end{array}$ & $\begin{array}{c}438^{* *} \\
(22)\end{array}$ \\
\hline $\begin{array}{l}\text { Observations } \\
\text { R-squared }\end{array}$ & $\begin{array}{l}4,603 \\
0.022\end{array}$ & $\begin{array}{l}4,603 \\
0.026\end{array}$ & $\begin{array}{l}4,603 \\
0.067\end{array}$ & $\begin{array}{l}4,603 \\
0.068\end{array}$ & $\begin{array}{l}3,650 \\
0.811\end{array}$ \\
\hline
\end{tabular}

significant at $5 \% ;{ }^{* *}$ significant at $1 \% ;+$ significant at $10 \%$ level. Robust SEs in parentheses. 
Table 3: Effects of information condition by gender

\begin{tabular}{|c|c|c|c|c|}
\hline Dependent Variable & $\begin{array}{c}\text { (1) } \\
\text { Price Quote }\end{array}$ & $\begin{array}{c}(2) \\
\text { Price Quote }\end{array}$ & $\begin{array}{c}\text { (3) } \\
\text { Price Quote }\end{array}$ & $\begin{array}{c}(4) \\
\text { Price Quote }\end{array}$ \\
\hline Informed, Women & $\begin{array}{l}-.45 \\
(5.4)\end{array}$ & $\begin{array}{l}-2.7 \\
(5.5)\end{array}$ & $\begin{array}{l}-2.8 \\
(5.4)\end{array}$ & $\begin{array}{l}-2.7 \\
(5.4)\end{array}$ \\
\hline Uninformè, & $\begin{array}{l}(5.4) \\
13^{*}\end{array}$ & $\begin{array}{l}(5.6) \\
11^{*}\end{array}$ & $\begin{array}{l}(5.5) \\
12^{*}\end{array}$ & $\begin{array}{l}(5.5) \\
11^{*}\end{array}$ \\
\hline Ūninformè, Men & $\begin{array}{r}-9.9+ \\
(5.3)\end{array}$ & $\begin{array}{l}-11^{-*} \\
(5.7)\end{array}$ & $\begin{array}{l}-11+ \\
(5.6)\end{array}$ & $\begin{array}{c}-10+ \\
(5.6)\end{array}$ \\
\hline Misinformed, Women & $\begin{array}{l}355^{* * *} \\
(5.3)\end{array}$ & $\begin{array}{l}34 \\
(5.6)\end{array}$ & $\begin{array}{l}34^{* * *} \\
(5.5)\end{array}$ & $\begin{array}{l}3 \overline{4}^{* *^{-}} \\
(5.5)\end{array}$ \\
\hline Misinformed, Men & $\begin{array}{l}33^{* * *} \\
(5.4)\end{array}$ & $\begin{array}{l}33^{* *} \\
(5.6)\end{array}$ & $\begin{array}{l}32^{* *}- \\
(5.5)\end{array}$ & $\begin{array}{l}33^{* *}- \\
(5.6)\end{array}$ \\
\hline Second Call & & & & $(5.4)$ \\
\hline $\begin{array}{l}\text { Week Fixed Effects } \\
\text { DMA Fixed Effects }\end{array}$ & & $-\bar{v}$ & 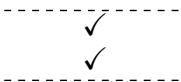 & $\checkmark$ \\
\hline Constant & $\begin{array}{c}393^{* *} \\
(3.8)\end{array}$ & $\begin{array}{c}3 \overline{9} 5^{* *} \\
(17)\end{array}$ & $\begin{array}{c}387^{* * *} \\
(17)\end{array}$ & $\begin{array}{c}388^{* *} \\
(17)\end{array}$ \\
\hline Obse & 4,603 & 4,603 & 4,603 & 4,603 \\
\hline R-squared & 0.026 & 0.030 & 0.070 & 0.071 \\
\hline
\end{tabular}

significant at $5 \%$;* significant at $1 \%$; + significant at $10 \%$ level. Robust SEs in parentheses.

Table 4: Likelihood of price concession by condition

\begin{tabular}{lccc|c} 
Condition & \multicolumn{5}{c}{ Did shop make a price concession? } \\
Observations* & No & Yes & Total \\
\hline Informed & 817 & $73.8 \%$ & $26.2 \%$ & $100.0 \%$ \\
Uninformed & 749 & $76.6 \%$ & $23.4 \%$ & $100.0 \%$ \\
Misinformed & 172 & $58.1 \%$ & $41.9 \%$ & $100.0 \%$ \\
\hline Total & 1738 & $73.6 \%$ & $26.4 \%$ & $100.0 \%$
\end{tabular}

* Note that the number of observations is unequal across conditions. This is because callers only ask for a concession if the initial price quote exceeds the benchmark price. Since the benchmark price in the misinformed condition is $\$ 510$ the initial price quote exceeds it less often than in the other two conditions. 
Table 5: Price concession results

\begin{tabular}{|c|c|c|c|c|c|}
\hline Dependent Variable & $\begin{array}{c}(1) \\
\text { I(Price } \\
\text { Concession } \\
>0)\end{array}$ & $\begin{array}{c}(2) \\
\mathrm{I}(\text { Price } \\
\text { Concession } \\
>0)\end{array}$ & $\begin{array}{c}(3) \\
\mathrm{I}(\text { Price } \\
\text { Concession } \\
>0)\end{array}$ & $\begin{array}{c}(4) \\
\mathrm{I}(\text { Price } \\
\text { Concession } \\
>0)\end{array}$ & $\begin{array}{c}(5) \\
\text { PriceConcession } \\
\text { (Tobit censored } \\
\text { at } 0 \text { ) }\end{array}$ \\
\hline Uninformed & $\begin{array}{l}-.027 \\
(.022)\end{array}$ & $\begin{array}{l}-.022 \\
(.021)\end{array}$ & & $\begin{array}{l}.013 \\
(.03)\end{array}$ & $\begin{array}{l}.81 \\
(14)\end{array}$ \\
\hline Misinformed & $\begin{array}{l}.14^{* *} \\
(.041)\end{array}$ & $\begin{array}{l}.16^{* *}- \\
(.041)\end{array}$ & & $\begin{array}{l}.076^{-} \\
(.061)\end{array}$ & $\begin{array}{l}38 \\
(23)\end{array}$ \\
\hline Women & & & $\begin{array}{l}.11^{* *}- \\
(.021)\end{array}$ & & \\
\hline Uninformed, Women & & & & $\begin{array}{l}.057^{*-} \\
(.029)\end{array}$ & $\begin{array}{l}2 \overline{2}+ \\
(13)\end{array}$ \\
\hline Informed, Women & & & & $\begin{array}{l}.12^{* * *} \\
(.031)\end{array}$ & $\begin{array}{l}35^{* * *} \\
(13)\end{array}$ \\
\hline Misinformed, Women & & & & $(.074)$ & $(24)$ \\
\hline RequestedConcession & $\begin{array}{c}\left(.000 \overline{6} 6^{* *}-\right. \\
(.00011)\end{array}$ & & & & \\
\hline RequestedConcession Decile ${ }^{--}$ & & $\begin{array}{l}-.0 \overline{4} 1 \\
(.048)\end{array}$ & $\begin{array}{l}-.055 \\
(.046)\end{array}$ & $\begin{array}{l}-.052 \\
(.047)\end{array}$ & $\begin{array}{l}.47^{-} \\
(10)\end{array}$ \\
\hline RequestedConcession Decile 3 & & $(.066)$ & $(.071)$ & $(.064)$ & $\begin{array}{c}-63^{* *} *- \\
(21)\end{array}$ \\
\hline RequestedConcession Decile 4 & & $(.051)$ & $\begin{array}{l}-.13^{* *-} \\
(.05)\end{array}$ & $\begin{array}{l}.14^{* *^{-}-} \\
(.05)\end{array}$ & $\begin{array}{l}-15 \\
(13)\end{array}$ \\
\hline RequestedConcession Decile 5 & & $\begin{array}{l}-.24^{*}- \\
(.046)\end{array}$ & $\begin{array}{l}-.25^{* *^{-}} \\
(.045)\end{array}$ & $\begin{array}{l}-.2 \overline{4}^{* \mathcal{F}^{-}-} \\
(.045)\end{array}$ & $\begin{array}{l}-4 \overline{3}^{*} \bar{*} \\
(14)\end{array}$ \\
\hline RequestedConcession Decile 6 & & $(.054)$ & $\begin{array}{l}-.27^{*}-{ }^{-} \\
(.053)\end{array}$ & $(.053)$ & $\begin{array}{l}-44^{*} \\
(19)\end{array}$ \\
\hline RequestedConcession Decile 7 & & $\begin{array}{l}-.2^{\bar{*} *^{-}} \\
(.05)\end{array}$ & $(.049)$ & $\begin{array}{l}-.22^{\text {s**- }}-{ }^{-1} \\
(.049)\end{array}$ & $\begin{array}{l}-15 \\
(15)\end{array}$ \\
\hline RequestedConcession Decile 8 & & $\begin{array}{l}-.26^{* *} \\
(.048)\end{array}$ & $\begin{array}{l}-.27 * *- \\
(.047)\end{array}$ & $\begin{array}{l}-.26^{* *^{*}-1} \\
(.048)\end{array}$ & $\begin{array}{l}-28 \\
(17)\end{array}$ \\
\hline RequestedConcession Decile $9^{--}$ & & $\begin{array}{l}-.27 \times \\
(.047)\end{array}$ & $\begin{array}{l}-.29^{*}{ }^{*}- \\
(.046)\end{array}$ & $\begin{array}{l}-.28^{*} x^{-} \\
(.047)\end{array}$ & $\begin{array}{l}-2 \overline{2} \\
(18)\end{array}$ \\
\hline RequestedConcession Decile $\overline{1}$ & & $\begin{array}{l}.26^{*} \\
(.048)\end{array}$ & (.047) & $\begin{array}{l}.27^{*} \text { * }^{-} \\
(.048)\end{array}$ & $(19)$ \\
\hline Constant & $\begin{array}{l}. \overline{3} \overline{4}^{*}{ }^{-} \\
(.021)\end{array}$ & $\begin{array}{l}43^{* *} \\
(.039)\end{array}$ & $\begin{array}{l}.39^{* *} \\
(.038)\end{array}$ & $\begin{array}{l}.37 * *- \\
(.041)\end{array}$ & $\begin{array}{c}-\overline{9} 3^{*} \\
(13)\end{array}$ \\
\hline $\begin{array}{l}\text { Observations } \\
\text { R-squared }\end{array}$ & $\begin{array}{l}1,738 \\
0.038\end{array}$ & $\begin{array}{l}1,738 \\
0.064\end{array}$ & $\begin{array}{l}1,738 \\
0.065\end{array}$ & $\begin{array}{l}1,738 \\
0.081\end{array}$ & 1,738 \\
\hline
\end{tabular}

${ }^{*}$ significant at $5 \% ;{ }^{* *}$ significant at $1 \% ;+$ significant at $10 \%$ level. Robust SEs in parentheses. 
Table 6: Experiment 2, initial price quote results

\begin{tabular}{|c|c|c|c|}
\hline Dependent Variable & $\begin{array}{c}\text { (1) } \\
\text { PriceQuote }\end{array}$ & $\begin{array}{c}(2) \\
\text { PriceQuote }\end{array}$ & $\begin{array}{c}\text { (3) } \\
\text { PriceQuote }\end{array}$ \\
\hline & Experiment 2: & Experiment 2: & Experiment 2: \\
\hline Downward-Biased & $\begin{array}{l}-7.4 \\
(4.6)\end{array}$ & $\begin{array}{l}-8.4 \\
(5.2)\end{array}$ & $\begin{array}{l}-8.9 \\
(8)\end{array}$ \\
\hline Uninformed, Women & & & $\begin{array}{l}-5.7 \\
(6.9)\end{array}$ \\
\hline Downward-Biased, Women & & & $\begin{array}{l}-5.2 \\
(6.9)\end{array}$ \\
\hline Week 13 & & $\begin{array}{l}-3.8 \\
(6.4)\end{array}$ & $\begin{array}{l}-3.6 \\
(6.4)\end{array}$ \\
\hline Week 14 & & $\begin{array}{c}-1.7 \\
(7)\end{array}$ & $\begin{array}{l}-1.5 \\
(7.1)\end{array}$ \\
\hline Week 15 & & $\begin{array}{l}-6.7 \\
(8.6)\end{array}$ & $\begin{array}{l}-6.5 \\
(8.6)\end{array}$ \\
\hline Week 16 & & $\begin{array}{l}-24+ \\
(14)\end{array}$ & $\begin{array}{l}-22^{-} \\
(14)\end{array}$ \\
\hline$\overline{\mathrm{D}} \overline{\mathrm{M}} \overline{\mathrm{A}}$ Fixed Effects & & $\sqrt{-1}$ & $\sqrt{-1}$ \\
\hline Constant & $\begin{array}{c}399^{* *--} \\
(3.3)\end{array}$ & $\begin{array}{c}3 \overline{8} \overline{4}^{* *^{-}-} \\
(13)\end{array}$ & $\begin{array}{c}3 \overline{8} 8^{* *-}- \\
(14)\end{array}$ \\
\hline Observations & 1,941 & 1,941 & 1,941 \\
\hline R-squared & 0.001 & 0.055 & 0.056 \\
\hline
\end{tabular}

significant at $5 \% ;{ }^{* *}$ significant at $1 \%$; significant at $10 \%$ level. Robust SEs in parentheses.

Table 7: Likelihood of price concession by condition

\begin{tabular}{lccc|c} 
& \multicolumn{5}{c}{ Did shop make a price concession? } \\
Condition & Observations* & No & Yes & Total \\
\hline Uninformed & 564 & $78.7 \%$ & $21.3 \%$ & $100.0 \%$ \\
Downward-Biased & 695 & $83.3 \%$ & $16.7 \%$ & $100.0 \%$ \\
\hline Total & 1259 & $81.2 \%$ & $18.8 \%$ & $100.0 \%$
\end{tabular}


Table 8: Experiment 2, price concession results

\begin{tabular}{|c|c|c|c|}
\hline Dependent Variable & $\begin{array}{c}(1) \\
\mathrm{I}(\text { Price } \\
\text { Concession } \\
>0)\end{array}$ & $\begin{array}{c}(2) \\
\mathrm{I}(\text { Price } \\
\text { Concession } \\
>0)\end{array}$ & $\begin{array}{c}(3) \\
\text { PriceConcession } \\
\text { (Tobit censored } \\
\text { at } 0 \text { ) }\end{array}$ \\
\hline Downward-Biased & $\begin{array}{l}-.021 \\
(.022)\end{array}$ & $\begin{array}{c}.03 \\
(.036)\end{array}$ & $\begin{array}{c}13 \\
(19)\end{array}$ \\
\hline 'uninformed, $\overline{\text { Women }}$ & & $\begin{array}{l}.0 \overline{6} 2+ \\
(.035)\end{array}$ & $\begin{array}{c}1 \overline{6} \\
(17)\end{array}$ \\
\hline Downward-Based, Women & & $\begin{array}{l}-.018 \\
(.029)\end{array}$ & $\begin{array}{l}-14 \\
(16)\end{array}$ \\
\hline RequestedConcession Decile 2 & $\begin{array}{l}.16^{\text {** }} \\
(.058)\end{array}$ & $\begin{array}{l}.16^{\text {* }} \\
(.057)\end{array}$ & $\begin{array}{l}-30^{*} \\
(15)\end{array}$ \\
\hline RequestedConcession Decile $\overline{3}$ & $\begin{array}{l}-.24^{* *}- \\
(.058)\end{array}$ & $\begin{array}{l}.24^{* *} \\
(.057)\end{array}$ & $\begin{array}{c}-\overline{5} \overline{8}^{* *}- \\
(20)\end{array}$ \\
\hline RequestedConcession Decile 4 & $\begin{array}{l}-.2^{\text {** }} \\
(.057)\end{array}$ & $\begin{array}{l}.19^{* * *} \\
(.057)\end{array}$ & $\begin{array}{r}-32+ \\
(17)\end{array}$ \\
\hline RequestedConcession Decile $\overline{5}$ & $\begin{array}{l}.31^{* *} \\
(.052)\end{array}$ & $\begin{array}{l}.31^{* *} \\
(.052)\end{array}$ & $\begin{array}{c}-78^{* *}- \\
(21)\end{array}$ \\
\hline RequestedConcession Decile 6 & $\begin{array}{l}. .29^{* *} \\
(.052)\end{array}$ & $\begin{array}{l}. .29^{* *} \\
(.052)\end{array}$ & $\begin{array}{c}-69^{* *} \\
(20)\end{array}$ \\
\hline RequestedConcession Decile 7 & $\begin{array}{l}-.36^{* *} \\
(.048)\end{array}$ & $\begin{array}{l}.37 * *-1 \\
(.048)\end{array}$ & $\begin{array}{c}-116^{* \bar{*}} \\
(24)\end{array}$ \\
\hline RequestedConcession Decile $\overline{8}$ & $\begin{array}{l}-.32^{* *} \\
(.054)\end{array}$ & $\begin{array}{l}. .32^{\text {** }} \\
(.053)\end{array}$ & $\begin{array}{c}-70^{* *} \\
(25)\end{array}$ \\
\hline${ }^{-}$RequestedConcession Decile $\overline{9}$ & $\begin{array}{l}-. \overline{3}^{* *} *^{-} \\
(.053)\end{array}$ & $\begin{array}{l}-.3^{* *} \\
(.052)\end{array}$ & $\begin{array}{l}-41+ \\
(22)\end{array}$ \\
\hline RequestedConcession Decile 10 & $\begin{array}{l}-.3^{* *}- \\
(.053)\end{array}$ & $\begin{array}{l}-.3^{* *} \\
(.052)\end{array}$ & $\begin{array}{l}-3 \overline{5} \\
(23)\end{array}$ \\
\hline Constant & $\begin{array}{l}.45^{* * *} \\
(.044)\end{array}$ & $\begin{array}{l}.41^{* *} \\
(.048)\end{array}$ & $\begin{array}{c}-\overline{8} \overline{3}^{*} \bar{*} \\
(17)\end{array}$ \\
\hline $\begin{array}{l}\text { Observations } \\
\text { R-squared }\end{array}$ & $\begin{array}{l}1,259 \\
0.073\end{array}$ & $\begin{array}{l}1,259 \\
0.076\end{array}$ & 1,259 \\
\hline
\end{tabular}

${ }^{*}$ significant at $5 \% ;{ }^{* *}$ significant at $1 \% ;+$ significant at $10 \%$ level. Robust SEs in parentheses. 


\section{Figures}

Figure 1: Summary of empirical predictions of price effects between genders
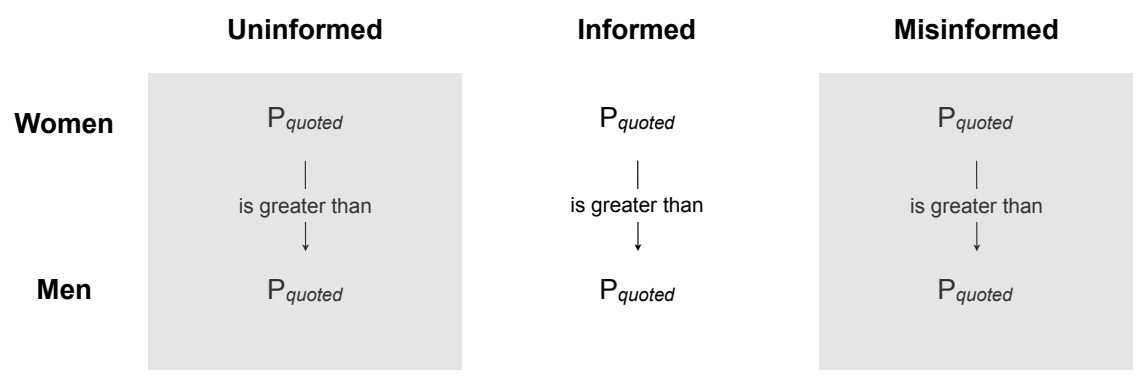

Figure 2: Summary of empirical predictions of price effects between conditions

Women Uninformed


Figure 3: Main experiment: Distribution of price quotes by condition
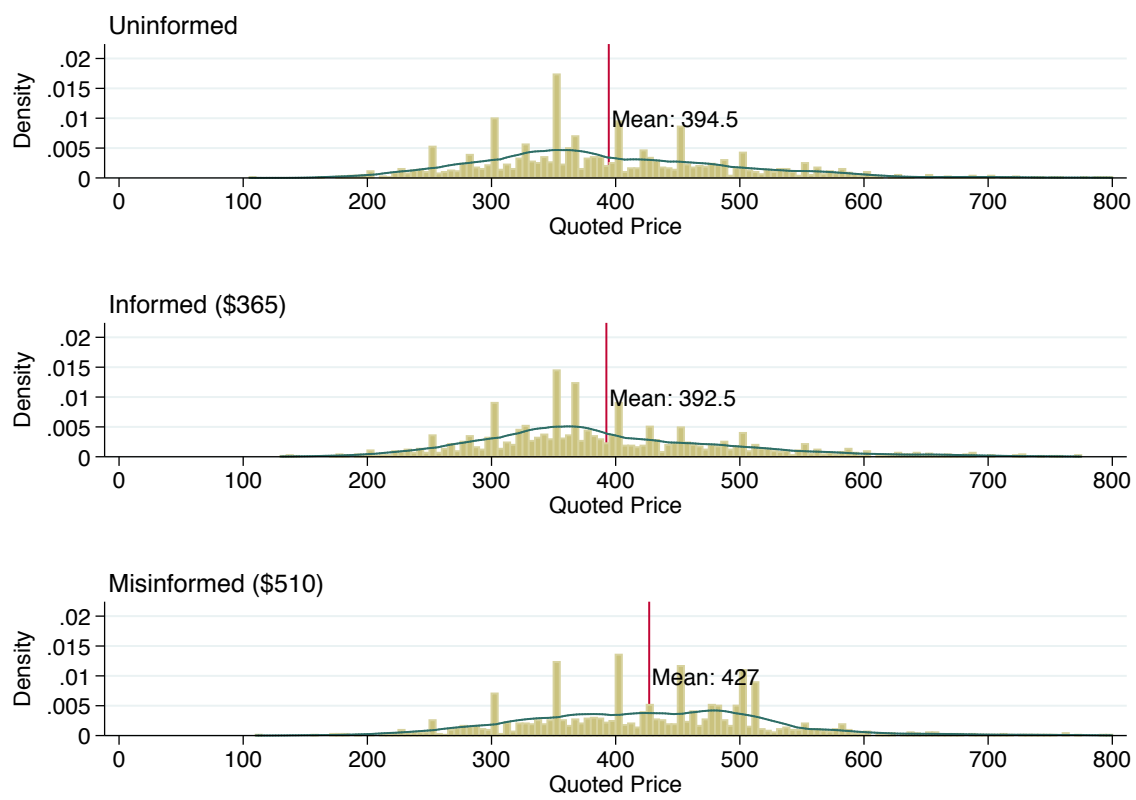
Figure 4: Distribution of price quotes by condition and gender
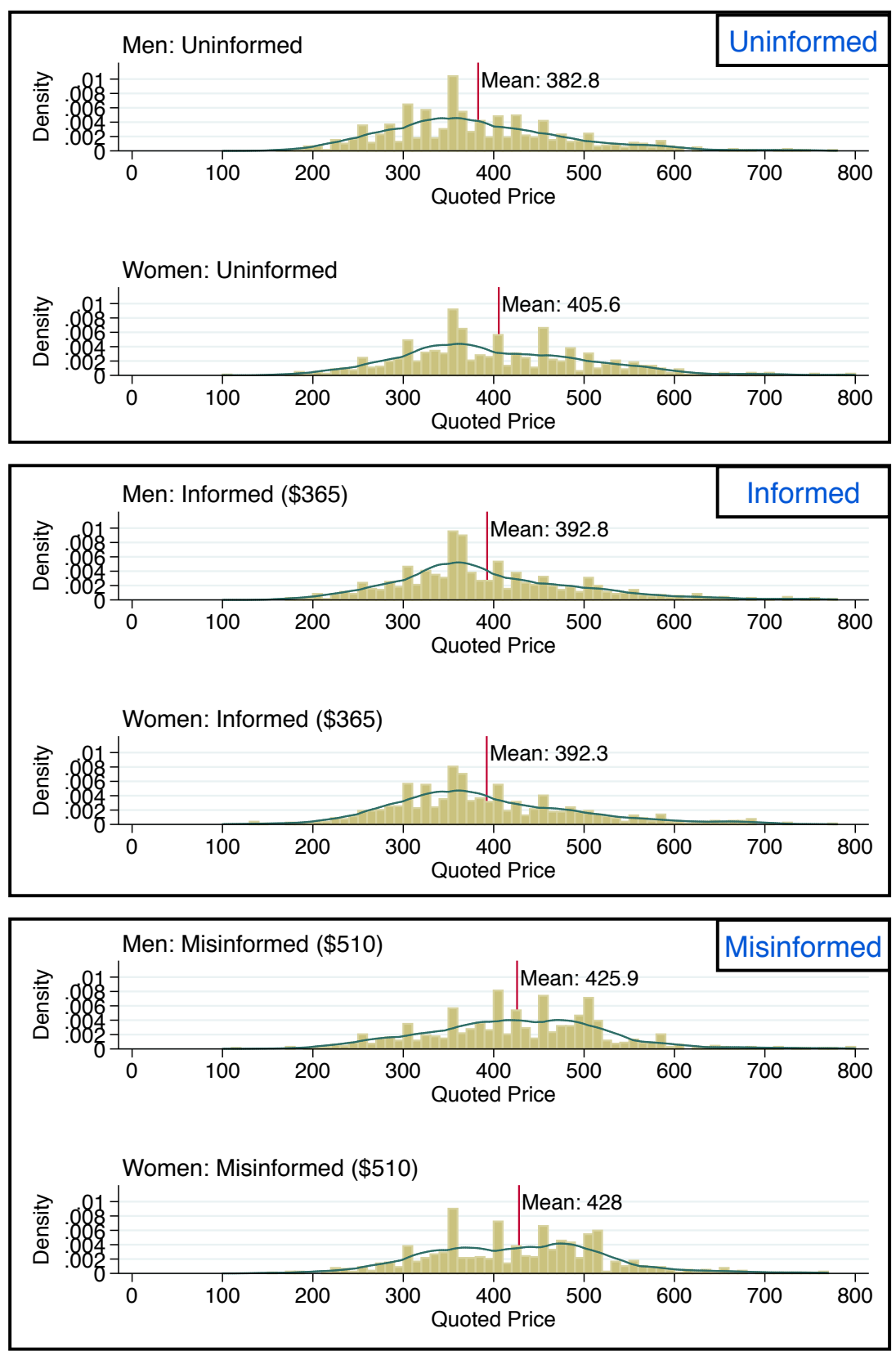
Figure 5: Summary of empirical results

\begin{tabular}{|c|c|c|c|c|c|}
\hline \multirow{3}{*}{ Women } & \multicolumn{2}{|l|}{ Uninformed } & \multicolumn{2}{|l|}{ Informed } & Misinformed \\
\hline & $\$ 405.6$ & $\underset{\text { than }}{\stackrel{\text { is greater }}{\longrightarrow}}$ & $\$ 392.3$ & $\frac{\text { is greater }}{\text { than }}$ & $\$ 428.0$ \\
\hline & $\begin{array}{c}\mid \\
\text { is greater than } \\
\downarrow\end{array}$ & & $\begin{array}{c}\text { I } \\
\text { is equal to } \\
\downarrow\end{array}$ & & $\begin{array}{c}\text { I } \\
\text { is equal to } \\
\downarrow\end{array}$ \\
\hline Men & $\$ 382.8$ & $\begin{array}{c}\text { is greater } \\
\text { than or } \\
\text { equal to }\end{array}$ & $\$ 392.8$ & $\frac{\text { is greater }}{\text { than }}$ & $\$ 425.9$ \\
\hline
\end{tabular}




\section{WEB APPENDIX}

\section{Outline of call center scripts}

- Dial number

- "Hello, my name is John/Jennifer. I have a leak in the radiator on my 2003 Camry and I need to replace it. Is that something you work on?"

- If the answer is no

- "Thank you" (and hang up)

- If the answer is yes

- "So I have a 6 Cylinder 2003 Toyota Camry LE."

- Uninformed Condition: "I have no idea how much it is to replace a radiator."

- Informed Condition: "I just visited the website AutoMD.com, and for this area they say the cost should be $\$ 365$ to replace the radiator on my car."

- Misinformed Condition: "I just visited the website AutoMD.com, and for this area they say the cost should be $\$ 510$ to replace the radiator on my car."

- Downward-Biased Condition: "I just visited the website AutoMD.com, and for this area they say the cost should be $\$ 310$ to replace the radiator on my car."

- "Could you tell me how much you charge?"

- If shop refuses to give quote over the phone type "Refused" in column I (do not leave column empty).

- "Thank you" (and hang up)

- Otherwise, insert amount into column I.

- "OK, thanks. Would that also include antifreeze liquid?"

- If the answer is "no":

- "Can you give me the price including antifreeze?" (If necessary, update amount in column I.)

- "OK, thanks. Would that also include a cooling system flush?"

- If the answer is "no":

- "Can you give me the price including a cooling system flush?" (If necessary, update amount in column I.)

- "OK, thanks. That is the total price without tax, right?"

- If the answer is "no":

Web Appendix-1 
- "Can you give me the total price before tax?" (If necessary, update amount in column I.)

- "Just to make sure: does the price include parts and labor?"

- If the answer is "yes":

- "OK, thank you"

- If the answer is "no":

- "Can you give me the total price before tax?" (If necessary, update amount in column I.)

- If the price in column I is LESS than or EQUAL to column $\mathrm{J}$ : ( $\$ 365$ for Informed and Uninformed, $\$ 510$ for Misinformed, $\$ 310$ for Downward-Biased Condition)

- "All right, let me think about this" (and hang up)

- If the price in column I is MORE than column $\mathrm{J}$ :

- "So, I have a question:"

- Uninformed Condition: "I just visited the website AutoMD.com, and for this area they say the cost should be $\$ 365$. Would you match this price?"

- Informed Condition: "Would you match the price of $\$ 365$ that the website AutoMD said it should cost in this area?"

- Misinformed Condition: "Would you match the price of $\$ 510$ that the website AutoMD said it should cost in this area?"

- Downward-Biased Condition: "Would you match the price of $\$ 310$ that the website AutoMD said it should cost in this area?"

- If the answer is "yes," type "yes" in column K

- If the answer is "no" with a REVISED offer, type amount of revised offer in column K. If they mention certain terms (proof/local shops) write them.

- If the answer is "no" WITHOUT a revised offer, type "no" in column K. If they mention certain terms (proof/local shops) write them.

- "All right, let me think about this" (and hang up) 


\section{Additional Tables}

Table A-1: Analysis of shops with two quotes

\begin{tabular}{|c|c|c|}
\hline Dependent Variable & $\begin{array}{c}\text { (1) } \\
\text { Men } \\
\text { Pricequote }\end{array}$ & $\begin{array}{c}(2) \\
\text { Women } \\
\text { Pricequote }\end{array}$ \\
\hline Uninformed & $\begin{array}{l}-2.8 \\
(5.1)\end{array}$ & $\begin{array}{c}7.5 \\
(4.7)\end{array}$ \\
\hline Misinformed & $\begin{array}{l}25^{*} \times \\
(5.1)\end{array}$ & $\left.27^{*} \times\right)$ \\
\hline Second Call & $\begin{array}{l}22 \\
(21)\end{array}$ & $\begin{array}{l}12 \\
(21)\end{array}$ \\
\hline $\begin{array}{l}\text { Week Fixed Effects } \\
\text { Shop Fixed Effects }\end{array}$ & $\checkmark$ & $\checkmark$ \\
\hline Constant & $\begin{array}{c}395 * * \\
(23)\end{array}$ & $\begin{array}{c}\overline{4} \overline{6} 0^{*}{ }^{-} \\
(32)\end{array}$ \\
\hline Observations & 1,626 & 2,024 \\
\hline R-squared & 0.842 & 0.795 \\
\hline
\end{tabular}

* significant at 5\%; ** significant at $1 \%$; + significant at $10 \%$ level. Robust SEs in parentheses. 
Table A-2: Effects of information condition by gender for first calls only

\begin{tabular}{|c|c|c|c|}
\hline Dependent Variable & $\begin{array}{c}\text { (1) } \\
\text { Price Quote }\end{array}$ & $\begin{array}{c}\text { (2) } \\
\text { Price Quote }\end{array}$ & $\begin{array}{c}(3) \\
\text { Price Quote }\end{array}$ \\
\hline Informed, Women & $\begin{array}{l}13+ \\
(7.7)\end{array}$ & $\begin{array}{c}12 \\
(7.8)\end{array}$ & $\begin{array}{c}9.7 \\
(7.7)\end{array}$ \\
\hline Uninformed, $\overline{\text { Women }}$ & $\begin{array}{l}20^{* *} \\
(7.8)\end{array}$ & $(8)$ & $\begin{array}{l}20 \\
(7.9)\end{array}$ \\
\hline Uninformed, Men & $\begin{array}{c}-1.9 \\
(7)\end{array}$ & $(7.2)$ & $\begin{array}{l}-1.2 \\
(7.1)\end{array}$ \\
\hline Misinformed, Women & $\begin{array}{l}53^{* *} \\
(7.2)\end{array}$ & $\begin{array}{l}54^{* *} \\
(7.4)\end{array}$ & $\begin{array}{l}54^{\text {*ै* }}- \\
(7.3)\end{array}$ \\
\hline Misinformed, Men & (7.1) & $\begin{array}{l}45^{* *} \\
(7.3)\end{array}$ & $\begin{array}{l}4 \overline{4}^{* *}{ }^{-} \\
(7.1)\end{array}$ \\
\hline $\begin{array}{l}\text { Week Fixed Effects } \\
\text { DMA Fixed Effects }\end{array}$ & & $v^{2}$ & $v^{2}$ \\
\hline Constant & $\begin{array}{c}\overline{3} 8 \overline{1}^{* *} \\
(5.6)\end{array}$ & $\begin{array}{c}384^{* *} \\
(17)\end{array}$ & $\begin{array}{c}376^{* *} \\
(18)\end{array}$ \\
\hline Observations & 2,680 & 2,680 & 2,680 \\
\hline R-squared & 0.040 & 0.042 & 0.082 \\
\hline
\end{tabular}

${ }^{*}$ significant at $5 \%$;* significant at $1 \%$; + significant at $10 \%$ level. Robust SEs in parentheses. 
Table A-3: Concession amount conditional on concession

\begin{tabular}{|c|c|}
\hline Dependent Variable & $\begin{array}{c}(5) \\
\text { PriceConcession } \\
\text { if Concession } \\
>0\end{array}$ \\
\hline Uninformed & $\begin{array}{c}4.1 \\
(6.5)\end{array}$ \\
\hline Misinformed & $\begin{array}{l}5.2^{-} \\
(7.2)\end{array}$ \\
\hline Uninformed, Women & $\begin{array}{l}3.4 \\
(4.8)\end{array}$ \\
\hline Informed, Women & $\begin{array}{l}5.3^{-} \\
(6.1)\end{array}$ \\
\hline Misinformed, Women & $\begin{array}{l}5.4^{-} \\
(4.7)\end{array}$ \\
\hline RequestedConcession Decile 2 & $\begin{array}{l}19^{*}- \\
(1.1)\end{array}$ \\
\hline RequestedConcession Decile 3 & $\begin{array}{l}27^{*} *{ }^{-} \\
(2.6)\end{array}$ \\
\hline RequestedConcession Decile 4 & $\begin{array}{l}36^{*} \\
(2.1)\end{array}$ \\
\hline RequestedConcession Decile 5 & $\begin{array}{l}57^{*}{ }^{-}- \\
(2.9)\end{array}$ \\
\hline RequestedConcession Decile 6 & $\begin{array}{l}73^{*} \text { * } \\
(5.2)\end{array}$ \\
\hline RequestedConcession Decile $7^{-}$ & $\begin{array}{l}94 \text { * } \\
(4.8)\end{array}$ \\
\hline RequestedConcession Decile 8 & $\begin{array}{c}121^{* *} \\
(7)\end{array}$ \\
\hline RequestedConcession Decile 9 & $\begin{array}{l}171^{* * *} \\
(6.7)\end{array}$ \\
\hline RequestedConcession Decile 10 & $\begin{array}{c}256^{* *} \\
(19)\end{array}$ \\
\hline Constant & $\begin{array}{l}4.1^{-} \\
(5.8)\end{array}$ \\
\hline $\begin{array}{l}\text { Observations } \\
\text { R-squared }\end{array}$ & $\begin{array}{c}458 \\
0.814\end{array}$ \\
\hline
\end{tabular}

\section{Robustness}

\section{Script codes}

Out of the 249 quotes where the agent had recorded the incorrect script code, 85 quotes were obtained at the beginning of the experiment using script wording that we changed after making some calls in a pre-test. These 85 calls recorded the pre-test script codes, indicating that the calls were probably made using the pre-test script wording. In the analysis presented in this paper we have already eliminated these 85 quotes. However, the remaining 164 quotes with incorrect script codes are still in the data. This is because the scripts to which the codes referred had identical wording to those that the agents should have used. ${ }^{32}$ Since all of these cases occurred during the first six weeks of data collection, they can only potentially affect the results from experiment 1.

To explore the robustness of our result to incorrect script code entries, we rerun the main regressions from experiment 1 (column 4 of Table 3, and columns 4 and 5 of Table 5) after dropping all 249 quotes with incorrect script codes. The results are reported in column 2 of Table A-5 and

\footnotetext{
${ }^{32}$ We changed the script code because we updated instructions on how to fill out the spreadsheet, not because the wording of the scripts themselves changed.
} 
columns 2 and 6 of Table A-6. While the point estimates change slightly, none of our conclusions are affected by dropping quotes with incorrect script codes. ${ }^{33}$

\section{Agents' comments: call-backs}

We reestimated our main specifications after eliminating all quotes for which an agent noted that the shop requested a call-back before the quote was obtained. The conclusions from experiment 1 do not change (see column 3 of Table A-5, columns 3 and 7 of Table A-6). ${ }^{34}$ Similarly, we did not find any significant changes in experiment 2 (see column 2 of Table A-7, columns 2 and 5 of Table A-8).

\section{Agents' comments: rough estimates}

We reestimated our main specifications after eliminating all quotes that were classified as "rough estimates". The conclusions from experiment 1 do not change; see column 4 of Table A-5, columns 4 and 8 of Table A-6. ${ }^{35}$ In experiment 2, the results in column 3 of Table A-7 and column 6 of Table A-8 are unchanged. However, the result that women are more likely to obtain a price concession in the uninformed condition falls in magnitude and is no longer statistically significant even at the $10 \%$ confidence level (see column 3 of Table A-8).

\footnotetext{
${ }^{33}$ The most significant differences in the results are in two p-values in Table A-5. The p-value for the "Uninformed, Women" coefficient goes from just over .05 to just under, while the p-value for the "Uninformed, Men" coefficient does the reverse.

${ }^{34}$ Again, the p-values of the "Uninformed, Women" and "Uninformed, Men" coefficients in Table A-5 vacillate between just over and just under .05, but with little change in the coefficients themselves.

${ }^{35}$ In Table A-5, the p-values on the "Uninformed, Women" and "Uninformed, Men" coefficients are now both just under .05.
} 
Table A-4: Price concession results with controls

\begin{tabular}{|c|c|c|c|}
\hline Dependent Variable & $\begin{array}{c}(1) \\
\mathrm{I}(\text { Price } \\
\text { Concession } \\
>0)\end{array}$ & $\begin{array}{c}(2) \\
\mathrm{I}(\text { Price } \\
\text { Concession } \\
>0)\end{array}$ & $\begin{array}{c}(3) \\
\text { Price } \\
\text { Concession if } \\
(\text { Tobit censored at } 0)\end{array}$ \\
\hline Uninformed & & $\begin{array}{l}.0036 \\
(.034)\end{array}$ & $\begin{array}{c}3 \\
(15)\end{array}$ \\
\hline Misinformed & & $\begin{array}{l}.064 \\
(.062)\end{array}$ & $\begin{array}{l}32 \\
(23)\end{array}$ \\
\hline Women & $\begin{array}{l}.096^{* *^{-}} \\
(.021)\end{array}$ & & \\
\hline Uninformed, Women & & $.051)$ & $\begin{array}{l}15 \\
(13)\end{array}$ \\
\hline Informed, Women & & $(.033)$ & $\begin{array}{l}31^{*} \\
(13)\end{array}$ \\
\hline Misinformed, Women & & $(.074)$ & $\begin{array}{l}48^{-} \\
(24)\end{array}$ \\
\hline RequestedConcession Decile 2 & $\begin{array}{l}-.0 \overline{4} \overline{8}^{--} \\
(.046)\end{array}$ & $\begin{array}{l}-.045 \\
(.047)\end{array}$ & $\begin{array}{l}2.9^{--} \\
(10)\end{array}$ \\
\hline RequestedConcession Decile 3 & $(.073)$ & $(.067)$ & $\begin{array}{c}-58^{* *} \\
(22)\end{array}$ \\
\hline RequestedConcession Decile 4 & $\begin{array}{l}-.12^{*-1} \\
(.05)\end{array}$ & $(.05)$ & $(13)$ \\
\hline RequestedConcession Decile 5 & $\begin{array}{l}-.24^{* *} \\
(.045)\end{array}$ & $\begin{array}{l}-.23^{* *^{-}} \\
(.046)\end{array}$ & $\begin{array}{c}-38^{* *}- \\
(14)\end{array}$ \\
\hline RequestedConcession Decile 6 & $(.052)$ & $\begin{array}{l}-.24^{* *^{-}} \\
(.053)\end{array}$ & $(18)$ \\
\hline RequestedConcession Decile 7 & $\begin{array}{l}-.22^{* *} \\
(.049)\end{array}$ & $\begin{array}{l}-.21^{*}{ }^{-} \\
(.049)\end{array}$ & $(15)$ \\
\hline RequestedConcession Decile 8 & $(.047)$ & $(.047)$ & $\begin{array}{r}-30+- \\
(17)\end{array}$ \\
\hline RequestedConcession Decile 9 & $(.046)$ & $\begin{array}{l}-.27^{* *} \\
(.047)\end{array}$ & $\begin{array}{l}-20^{-} \\
(18)\end{array}$ \\
\hline RequestedConcession Decile 10 & $(.047)$ & $\begin{array}{l}-.26^{*-1} \\
(.048)\end{array}$ & $\begin{array}{l}16 \\
(19)\end{array}$ \\
\hline Second ${ }^{-}$Call & $\begin{array}{l}.04 \overline{6}^{-} \\
(.04)\end{array}$ & $\begin{array}{l}.049^{--} \\
(.04)\end{array}$ & $\begin{array}{l}21 \\
(13)\end{array}$ \\
\hline $\begin{array}{l}\text { Week Fixed Effects } \\
\text { DMA Fixed Effects }\end{array}$ & $\checkmark$ & $\checkmark$ & $\checkmark$ \\
\hline Constant & $\begin{array}{l}.63^{* *} \\
(.12)\end{array}$ & $\begin{array}{l}.63^{* *} \\
(.12)\end{array}$ & $\begin{array}{l}-6 \\
(35)\end{array}$ \\
\hline $\begin{array}{l}\text { Observations } \\
\text { R-squared }\end{array}$ & $\begin{array}{l}1,738 \\
0.104\end{array}$ & $\begin{array}{l}1,738 \\
0.117\end{array}$ & 1,738 \\
\hline
\end{tabular}


Table A-5: Initial price quote results, robustness checks

\begin{tabular}{|c|c|c|c|c|}
\hline Robustness Check & $\begin{array}{c}\text { (1) } \\
\text { Original Results }\end{array}$ & $\begin{array}{c}(2) \\
\text { Script Code }\end{array}$ & $\begin{array}{c}(3) \\
\text { Call-Back }\end{array}$ & $\begin{array}{c}(4) \\
\text { Rough Estimate }\end{array}$ \\
\hline Dependent Variable & Price Quote & Price Quote & Price Quote & Price Quote \\
\hline Informed, Women & $\begin{array}{l}-2.7 \\
(5.4)\end{array}$ & $\begin{array}{l}-3.7 \\
(5.5)\end{array}$ & $\begin{array}{c}-3.3 \\
(6)\end{array}$ & $\begin{array}{l}-2.8 \\
(5.6)\end{array}$ \\
\hline Uninformed, Women & $\begin{array}{l}11^{*} \\
(5.5)\end{array}$ & $\begin{array}{l}9.7+ \\
(5.6)\end{array}$ & $\begin{array}{l}13^{*-} \\
(6.2)\end{array}$ & $\begin{array}{l}11+ \\
(5.6)\end{array}$ \\
\hline Uninformed, Men & $\begin{array}{l}-10+ \\
(5.6)\end{array}$ & $\begin{array}{l}-12^{*} \\
(5.8)\end{array}$ & $\begin{array}{l}-11+ \\
(6.2)\end{array}$ & $\begin{array}{l}-1 \overline{1} \\
(5.8)\end{array}$ \\
\hline Misinformed, Women & $\begin{array}{l}34^{*} *^{-} \\
(5.5)\end{array}$ & $\begin{array}{l}33^{* *} \\
(5.6)\end{array}$ & $\begin{array}{l}34^{* *} \\
(5.9)\end{array}$ & $\begin{array}{l}333^{* *} \\
(5.6)\end{array}$ \\
\hline Misinformed, Men & $\begin{array}{l}33 \times *{ }^{2} \\
(5.6)\end{array}$ & $\begin{array}{l}311^{* *} \\
(5.6)\end{array}$ & $\begin{array}{l}33^{* *} \\
(6.1)\end{array}$ & $\begin{array}{l}32^{\text {*.*. }} \\
(5.8)\end{array}$ \\
\hline Second Call & (5.4) & $\begin{array}{l}15.5) \\
(5)^{*}-1\end{array}$ & $(6.1)$ & $(5.5)$ \\
\hline $\begin{array}{l}\text { Week Fixed Effects } \\
\text { DMA Fixed Effects }\end{array}$ & $\sqrt{-1}$ & $\begin{array}{ll}-1 \\
\checkmark \\
-\end{array}$ & $\checkmark$ & $\begin{array}{l}-1 \\
-1 \\
- \\
-1\end{array}$ \\
\hline Constant & $\begin{array}{c}388^{* *} \\
(17)\end{array}$ & $\begin{array}{c}38 \overline{9}^{* *} \\
(17)\end{array}$ & $\begin{array}{c}\overline{3} 8 \overline{9}^{* *} \\
(19)\end{array}$ & $\begin{array}{c}390^{* * *} \\
(17)\end{array}$ \\
\hline Observations & 4,603 & 4,439 & 4,022 & 4,455 \\
\hline R-squared & 0.071 & 0.071 & 0.073 & 0.073 \\
\hline
\end{tabular}

${ }^{*}$ significant at $5 \%$;* significant at $1 \%$; + significant at $10 \%$ level. Robust SEs in parentheses. 


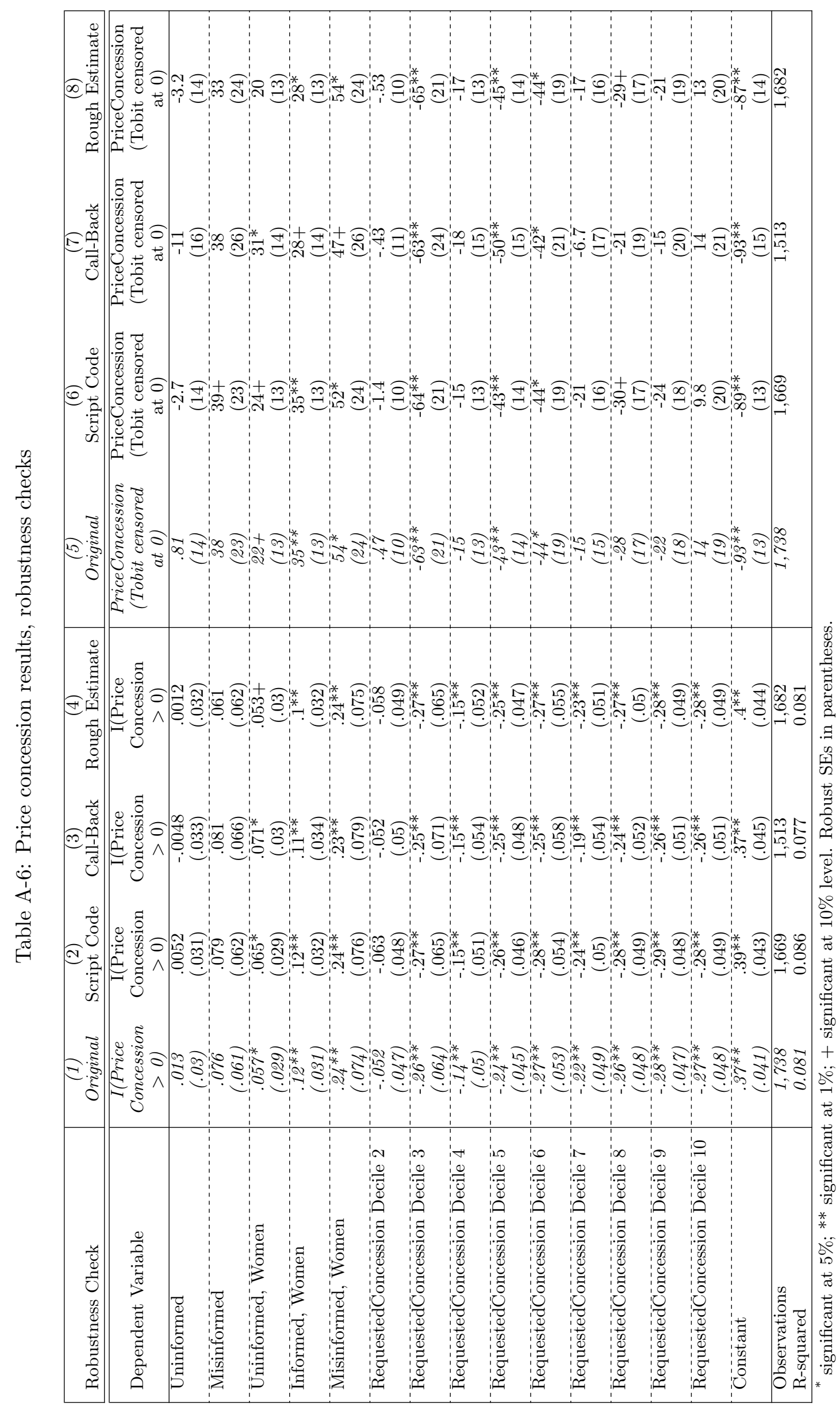

Web Appendix-9 
Table A-7: Experiment 2, initial price quote results, robustness checks

\begin{tabular}{|c|c|c|c|}
\hline Robustness Check & $\begin{array}{c}\text { (1) } \\
\text { Original Results }\end{array}$ & $\begin{array}{c}(2) \\
\text { Call-Back } \\
\end{array}$ & $\begin{array}{c}(3) \\
\text { Rough Estimate }\end{array}$ \\
\hline Dependent Variable & Price Quote & Price Quote & Price Quote \\
\hline Downward-Biased & $\begin{array}{l}-8.9 \\
(8)\end{array}$ & $\begin{array}{c}-14 \\
(9.3)\end{array}$ & $\begin{array}{l}-8.9 \\
(8.1)\end{array}$ \\
\hline Uninformed, Women & $\begin{array}{l}-5.7 \\
(6.9)\end{array}$ & $\begin{array}{l}-11 \\
(7.9)\end{array}$ & $\begin{array}{l}-5.2 \\
(7)\end{array}$ \\
\hline Downward-Biased, Women & $\begin{array}{l}-5.2 \\
(6.9)\end{array}$ & $\begin{array}{l}-3 \\
(7.7)\end{array}$ & $(7.1)$ \\
\hline Week 13 & $(6.4)$ & $\begin{array}{c}-3.2 \\
(7)\end{array}$ & $\begin{array}{l}-4.4 \\
(6.5)\end{array}$ \\
\hline Week 14 & $\begin{array}{l}-1.5 \\
(7.1)\end{array}$ & $\begin{array}{l}-3.8 \\
(7.9)\end{array}$ & $\begin{array}{l}-1.9 \\
(7.2)\end{array}$ \\
\hline Week 15 & $\begin{array}{l}-6.5 \\
(8.6)\end{array}$ & $(9.5)$ & $\begin{array}{l}-5.4 \\
(8.9)\end{array}$ \\
\hline Week 16 & $\begin{array}{l}-2 \overline{2} \\
(14)\end{array}$ & $\begin{array}{l}-38^{* 3 *}- \\
(15)\end{array}$ & $\begin{array}{l}-\overline{2} \overline{3}^{-} \\
(14)\end{array}$ \\
\hline$\overline{\mathrm{D}} \overline{\mathrm{M}} \overline{\mathrm{F}} \mathrm{F}$ Fixed Effects & $a^{-1}$ & $\checkmark$ & $\checkmark$ \\
\hline Constant & $\begin{array}{c}388^{* *} \\
(14)\end{array}$ & $\begin{array}{c}3 \overline{9} 5^{* *-} \\
(16)\end{array}$ & $\begin{array}{c}389^{* *-} \\
(14)\end{array}$ \\
\hline $\begin{array}{l}\text { Observations } \\
\text { R-squared }\end{array}$ & $\begin{array}{l}1,941 \\
0,056\end{array}$ & $\begin{array}{l}1,629 \\
0,061\end{array}$ & $\begin{array}{l}1,864 \\
0.055\end{array}$ \\
\hline
\end{tabular}

significant at 5\%; ** significant at $1 \%$; significant at $10 \%$ level. Robust SEs in parentheses. 
Table A-8: Experiment 2, price concession results, robustness checks

\begin{tabular}{|c|c|c|c|c|c|c|}
\hline Robustness Check & $\begin{array}{c}(1) \\
\text { Original }\end{array}$ & $\begin{array}{c}(2) \\
\text { Call-Back }\end{array}$ & $\begin{array}{c}(3) \\
\text { Rough Estimate }\end{array}$ & $\begin{array}{c}\text { (4) } \\
\text { Original }\end{array}$ & $\begin{array}{c}(5) \\
\text { Call-Back }\end{array}$ & $\begin{array}{c}(6) \\
\text { Rough Estimate }\end{array}$ \\
\hline Dependent Variable & $\begin{array}{c}\text { I(Price } \\
\text { Concession } \\
>0)\end{array}$ & $\begin{array}{c}\mathrm{I}(\text { Price } \\
\text { Concession } \\
>0)\end{array}$ & $\begin{array}{c}\mathrm{I}(\text { Price } \\
\text { Concession } \\
>0)\end{array}$ & $\begin{array}{c}\text { PriceConcession } \\
\text { (Tobit censored } \\
\text { at 0) }\end{array}$ & $\begin{array}{l}\text { PriceConcession } \\
\text { (Tobit censored } \\
\text { at } 0 \text { ) }\end{array}$ & $\begin{array}{l}\text { PriceConcession } \\
\text { (Tobit censored } \\
\text { at } 0 \text { ) }\end{array}$ \\
\hline Downward-Biased & $\begin{array}{c}.03 \\
(.036)\end{array}$ & $\begin{array}{l}.037 \\
(.043)\end{array}$ & $\begin{array}{l}016 \\
.04)\end{array}$ & $\begin{array}{c}13 \\
(19)\end{array}$ & $\begin{array}{l}13 \\
(22)\end{array}$ & $\begin{array}{c}4.5 \\
(19)\end{array}$ \\
\hline Uninformed, Women & $\begin{array}{l}.062+ \\
(.035)\end{array}$ & $\begin{array}{l}.068+ \\
(.039)\end{array}$ & $\begin{array}{l}.044^{--} \\
(.037)\end{array}$ & $(17)$ & $(19)$ & $\begin{array}{l}6.2^{-} \\
(17)\end{array}$ \\
\hline Downward-Based, Women & $\begin{array}{l}. .018 \\
(.029)\end{array}$ & $\begin{array}{l}-.014 \\
(.033)\end{array}$ & $\begin{array}{l}-.0 \overline{2} \overline{2}^{-} \\
(.03)\end{array}$ & $(16)$ & $\begin{array}{l}-1 \overline{1} \\
(18)\end{array}$ & $\begin{array}{l}-15 \\
(16)\end{array}$ \\
\hline RequestedConcession Decile $\overline{2}$ & $\begin{array}{l}\left(.1 \overline{6}^{* *}\right. \\
(.057)\end{array}$ & $\begin{array}{l}-.22^{*_{*}^{-}} \\
(.063)\end{array}$ & $\begin{array}{c}.18^{* *} \\
(.06)\end{array}$ & $\begin{array}{l}-30^{*} \\
(15)\end{array}$ & $\begin{array}{l}-46^{* *^{-}} \\
(17)\end{array}$ & $(15)$ \\
\hline RequestedConcession Decile $\overline{3}$ & $\begin{array}{l}-.044^{* *} \\
(.057)\end{array}$ & $\begin{array}{l}-.25^{* *^{-}} \\
(.067)\end{array}$ & $\begin{array}{c}-.26 * * \\
(.06)\end{array}$ & $\begin{array}{l}-58^{* *}- \\
(20)\end{array}$ & $\begin{array}{c}-56^{* *^{-}} \\
(22)\end{array}$ & $\begin{array}{c}-59^{* *--} \\
(19)\end{array}$ \\
\hline RequestedConcession Decile 4 & $\begin{array}{l}-.1 \overline{9}^{* *} *^{-} \\
(.057)\end{array}$ & $\begin{array}{l}-.21^{*-x^{-}} \\
(.064)\end{array}$ & $\begin{array}{l}-.23^{* *} \\
(.059)\end{array}$ & $(17)$ & $(18)$ & $\begin{array}{l}-39^{*} \\
(17)\end{array}$ \\
\hline RequestedConcession Decile 5 & $\begin{array}{l}(.052) \\
-(.05 *-\end{array}$ & $\begin{array}{l}-.32^{* *^{-}} \\
(.06)\end{array}$ & $\begin{array}{l}-.34 * *-1.74 \\
(.054)\end{array}$ & $\begin{array}{l}-17 \overline{8}+7^{-} \\
(21)\end{array}$ & $\begin{array}{l}-76^{* *^{-}} \\
(22)\end{array}$ & $\begin{array}{l}-84^{* \pi^{-}-} \\
(21)\end{array}$ \\
\hline RequestedConcession Decile $\overline{6}$ & $\begin{array}{l}-. \overline{2} \overline{9}^{* *-} \\
(.052)\end{array}$ & $\begin{array}{l}-.31^{* *}- \\
(.059)\end{array}$ & $(.054)$ & $\begin{array}{l}-\overline{6} \overline{9}^{* *^{-}} \\
(20)\end{array}$ & $\begin{array}{c}-70^{* *}{ }^{-} \\
(22)\end{array}$ & $\begin{array}{c}-74^{* *--} \\
(20)\end{array}$ \\
\hline RequestedConcession Decile 7 & $\begin{array}{l}(. \overline{3} \overline{7} * *- \\
(.048)\end{array}$ & $\begin{array}{l}-.4^{*-*}- \\
(.054)\end{array}$ & $\begin{array}{c}.39 * * \\
(.05)\end{array}$ & $\begin{array}{c}-116^{* *} \\
(24)\end{array}$ & $\begin{array}{c}-122^{* * *} \\
(26)\end{array}$ & $\begin{array}{c}-116^{* *^{--}} \\
(24)\end{array}$ \\
\hline RequestedConcession Decile 8 & $\begin{array}{l}-. \overline{3} 2^{* * *} \\
(.053)\end{array}$ & $\begin{array}{l}-.34^{* *-} \\
(.061)\end{array}$ & $\begin{array}{l}-.35^{* * *-} \\
(.056)\end{array}$ & $\begin{array}{l}(25) \\
(25)^{*}+-\end{array}$ & $\begin{array}{l}-67^{*} \\
(28)\end{array}$ & $\begin{array}{c}-70^{* *-1} \\
(25)\end{array}$ \\
\hline RequestedConcession Decile $\overline{9}$ & $\begin{array}{l}-.3 * *- \\
(.052)\end{array}$ & $\begin{array}{l}-.32^{*}{ }^{-1} \\
(.06)\end{array}$ & $\begin{array}{l}-.33^{* *} \\
(.055)\end{array}$ & $\begin{array}{l}-41+ \\
\text { (22) }\end{array}$ & $\begin{array}{l}-39^{-} \\
(24)\end{array}$ & $\begin{array}{c}-42+- \\
(22)\end{array}$ \\
\hline RequestedConcession Decile 10 & $\begin{array}{l}-.3 * *- \\
(.052)\end{array}$ & $\begin{array}{l}-.34^{* *}- \\
(.059)\end{array}$ & $\begin{array}{l}-.33^{* *} \\
(.054)\end{array}$ & $\begin{array}{l}-\overline{3} 5 \\
(23)\end{array}$ & $\begin{array}{l}-4 \overline{3}+ \\
(25)\end{array}$ & $\begin{array}{c}-44+ \\
(23)\end{array}$ \\
\hline Constant & $\begin{array}{l}.41 *{ }^{-1} \\
(.048)\end{array}$ & $\begin{array}{l}.43^{* *}- \\
(.056)\end{array}$ & $\begin{array}{l}. \overline{4} 5^{* *}-1 \\
(.052)\end{array}$ & $\begin{array}{l}-8 \overline{3} * x^{-} \\
(17)\end{array}$ & $\begin{array}{c}-78^{* *^{-}} \\
(19)\end{array}$ & $\begin{array}{l}-67^{*}{ }^{-} \\
(17)\end{array}$ \\
\hline $\begin{array}{l}\text { Observations } \\
\text { R-squared }\end{array}$ & $\begin{array}{l}1,259 \\
0.076\end{array}$ & $\begin{array}{l}1,054 \\
0.077\end{array}$ & $\begin{array}{l}1,205 \\
0.084\end{array}$ & 1,259 & 1,054 & 1,205 \\
\hline
\end{tabular}

${ }^{*}$ significant at 5\%; ${ }^{* *}$ significant at $1 \%$; significant at $10 \%$ level. Robust SEs in parentheses. 


\section{Agents' comments: inconsistent call behavior}

To understand the context of this problem, recall that the script calls for a radiator replacement. In pre-testing we identified that a radiator replacement always requires new antifreeze and often (but not always) requires a cooling system flush. To reduce the variance in repair quotes we tried to standardize quotes by asking shops whether the quote included new antifreeze and a cooling system flush, and if not, to requote the price to include these items. To be precise, after the shop quoted the initial price the agent would say, "OK, thanks. Would that also include antifreeze liquid? [If the answer is "no"]: Can you give me the price including antifreeze? [If necessary, adjust price.] OK, thanks. Would that also include a cooling system flush? [If the answer is "no"]: Can you give me the price including a cooling system flush? [If necessary, adjust price.]"

Regrettably, in copying the script into a flowchart format, as requested by the call center, we instructed agents to say (differences are underlined), "OK, thanks. Would that also include antifreeze liquid? [If the answer is "no"]: Can you give me the price including antifreeze? [If necessary, adjust price.] OK, thanks. Would that also include a cooling system flush? [If the answer is "no"]: Can you give me the price including antifreeze? [If necessary, adjust price.]" In other words, while agents asked whether the price included a cooling system flush, they were not instructed to request a price that included the flush.

This mistake would be of serious concern if it had only been present in some scripts (conditions) but not others. However, the error was uniformly present across all conditions. The likely effect of the mistake is to increase the variance of price quotes, because some of the quotes would include a cooling system flush while others do not. This is likely to have decreased the power of our estimates.

Another consequence is that the mistake creates some room for interpretation by the agents. Specifically, while agents are instructed to follow the script exactly, some agents might perceive an inconsistency and therefore request an updated price including the cooling system flush, even if they were not instructed to do so. To investigate whether this occurred, we analyzed how frequently agents made reference in the comment field of the spreadsheet to accounting for a cooling system flush when requesting price quotes. The results from this analysis are in Table A-9.

Table A-9: Percentage of calls in which agent notes that price quote includes cooling system flush

\begin{tabular}{|c|c|c|c|c|c|c|c|c|c|}
\hline & \multicolumn{7}{|c|}{ Agent ID } \\
Week & 1 & 2 & 3 & 4 & 5 & 6 & 7 & 8 & 9 \\
\hline \hline 1 & 0 & 0 & 0 & 0 & 0 & 0 & 0 & 0 & 0 \\
2 & 0 & 0 & 0 & 0 & 17 & 0 & 0 & 14 & 0 \\
3 & 0 & 0 & 0 & 0 & 0 & 0 & 0 & 0 & 0 \\
4 & 1 & 0 & 0 & 0 & 19 & 1 & 0 & 0 & 1 \\
5 & 0 & 0 & 0 & 0 & 27 & 2 & 0 & 2 & 0 \\
6 & 2 & 0 & 0 & 0 & 24 & 0 & 0 & 0 & 0 \\
7 & 0 & 0 & 0 & 0 & 9 & 0 & 0 & 5 & 0 \\
8 & 0 & 0 & 0 & 0 & 5 & 1 & 0 & 0 & 0 \\
9 & 0 & 0 & 0 & 0 & 0 & 0 & 0 & 0 & 0 \\
10 & 0 & 0 & 0 & 0 & 0 & 0 & 0 & 0 & 0 \\
11 & 0 & 0 & 0 & 0 & 6 & 0 & 0 & 6 & 0 \\
12 & 0 & 0 & 0 & 0 & 2 & 1 & 0 & 15 & 0 \\
13 & 0 & 0 & 0 & 0 & 6 & 0 & 0 & 28 & 3 \\
14 & 0 & 0 & 0 & 0 & 8 & 1 & 0 & 12 & 8 \\
15 & 0 & 0 & 0 & 0 & 3 & 1 & 0 & 15 & 0 \\
16 & 0 & 0 & 0 & 0 & 0 & 0 & 0 & 11 & 0 \\
\hline
\end{tabular}

As we can see from these results, most agents never refer to a cooling system flush. Agents 5 
and 8 are much more likely to mention accounting for a cooling system flush when requesting price quotes, but not equally across all weeks of the experiment. Agent 5 seems to have accounted for a cooling system flush during the first half of the experiment but followed the script more closely during the second half. Agent 8 exhibits the opposite pattern: the agent seems to have accounted for a cooling system flush during the second half of the experiment but not during the first half. ${ }^{36}$ Agents 5 and 8 are both male, a detail whose relevance will become apparent shortly.

We account for the variation in agent behavior by using three different approaches. First, we add the information in Table A-9 as a control variable in all estimations. This means that for each agent in each week we control for the percentage of calls in which the agent refers to accounting for a cooling system flush when requesting price quotes. We also add the percentage squared in this specification. Second, we eliminate all observations for an agent in a week in which that agent refers to accounting for a cooling system flush more than $7.5 \%$ of the time, the 90 th percentile in Table A-9. Third, we eliminate all observations associated with agents 5 and 8 from the sample. That is, we remove observations where these agents' behavior was inconsistent compared to other agents, but also instances where they behaved in accordance with other agents. Removing these two agents from the dataset altogether eliminates $25 \%$ of the observations from our sample.

Table A-10 reports the results of comparing the quoted prices across the different conditions of experiment 1, using the three different methods to account for agents' inconsistent behavior with respect to cooling system flush. Column 1 presents the original results from column 4 of Table 2, and columns 2-4 reestimate this specification in three variations of accounting for flush references: controlling for flush reference, eliminating agent-weeks with a high frequency of flush references, and eliminating the two inconsistent agents altogether. The results remain unchanged. Specifically, there is no statistical difference between the average price quotes in the informed and the uninformed conditions. In addition, there is no change in the effect of the misinformed condition, which remains about $\$ 35$ higher than the informed condition.

Table A-11 reports on the results of reestimating Equation 8 by incorporating the three approaches for accounting for a flush reference. Column 1 presents the original results from column 4 of Table 3, and columns 2-4 reestimate this specification in three variations of accounting for flush references. Upon first inspection, it appears that many of the condition-gender interaction terms that capture our main results have changed. Closer inspection reveals that the results have not changed by as much as initially appears.

We turn our attention to column 2 of Table A-11. The "\% Flush Reference" and "\% Flush Reference Squared" coefficients imply that the initial price quotes for an agent-week in which the agent refers to a cooling system flush in $5 \%$ of his calls will be higher by $\$ 21.38$ on average. For a $10 \%$ flush reference rate, the implied average effect on the initial price quote is a $\$ 33.61$ increase; $\$ 30.64$ for a flush reference rate of $20 \%$.

The second point to note is that agents 5 and 8 , the agents who had the highest flush reference rates, were male. Given the effects described in the previous paragraph, these agents may well have recorded higher average initial quotes than the remaining three male agents, since agents 5 and 8 appear to have more often recorded a price quote that included a cooling system flush, an add-on that would increase a price quote.

\footnotetext{
${ }^{36}$ The reader may note a low percentage for agent 5 during weeks 1 and 3 and a high percentage for agent 8 during week 2. During these weeks these two agents made very few calls, resulting in high sampling variation.
} 
Figure A-1: Predicted average initial price quotes by condition and gender, full sample ("Col 1") and subsample ("Col 4") estimates

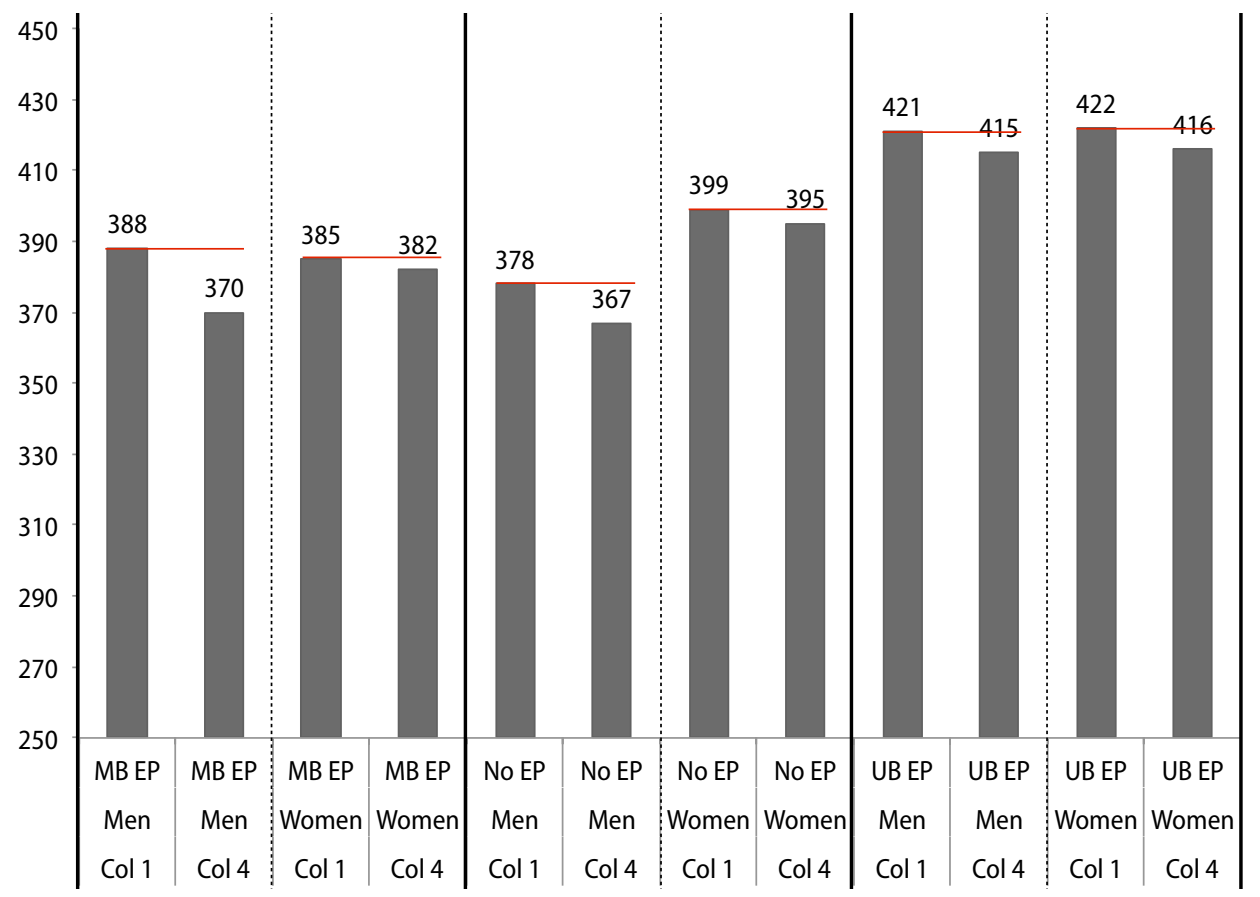

This means that in column 4 of Table A-11, the specification in which we eliminate agents 5 and 8 from the sample, we redefine our benchmark group (male agents) to be a subgroup of male agents who would be expected to obtain lower price quotes on average (because they did not include cooling system flushes) than did agents 5 and 8 . This can be seen in the estimated constant term of $\$ 370$ (which captures the average for male callers in the informed condition) in column 4 compared to an estimated constant term of $\$ 388$ in column 1.

In column 4, many of the condition-gender interaction terms have higher estimated coefficients than in column 1. But this is in large part because they estimate the incremental effect relative to the "left out" group (male callers in the informed condition), which is a lower average price quote group in column 4 than in column 1 because the (male) high flush reference agents are not included in the sample in column 4. These effects can be seen visually in Figure A-1, which plots the average initial price quotes for each of our six condition-gender interactions as predicted by the estimates in Table A-11. For each condition-gender combination, the bar on the left shows the predicted initial price quotes based on the estimates in column 1, while the bar on the right is based on column 4. It is noteworthy that the predicted average initial price quotes for women are very similar in the two specification, which we might have expected since the sample of women callers did not change between columns 1 and 4.

What this tells us is that the differences between outcomes obtained by men and women, and the differences in outcomes between the misinformed and informed conditions may be somewhat bigger than what we have reported in the main section of the paper. However, this is for the very simple reason that some of the male agents in the sample had artificially high initial price quotes because they were more likely to include a cooling system flush in the price quote they recorded. 
Table A-12 reports on the results of price concession incidence and levels, accounting for the flush references. Columns 1 and 5 present the original results from columns 4 and 5 of Table 5 , and columns 2-4 and 6-8 reestimate these specifications in three variations of accounting for flush references. The results after adding the flush reference variables as controls and eliminating agents in weeks where their relative frequency of flush reference was high are consistent with the original results that overall, women are more likely to obtain price concessions. In these specifications, the result for women in the uninformed condition becomes stronger $(p<0.05)$. In the specification where we eliminate agents 5 and 8 , the directional result that women are more likely to obtain price concessions remains, but the results are statistically weaker for all of the experimental conditions, and insignificant for the uninformed condition.

Table A-13 and Table A-14 report the analysis of experiment 2 while accounting for the flush reference. Column 1 in Table A-13 presents the original results from column 3 of Table 6, and columns 2-4 reestimate this specification in three variations of accounting for flush references. As in Table 6, the price quotes in the downward-biased condition are not statistically different than in the uninformed condition. When adding the condition and gender interactions, we again do not find significant differences between women and men.

Table A-14 reports the results of price concession incidence and levels in experiment 2, accounting for the flush references. Columns 1 and 5 present the original results from columns 2 and 3 of Table 8, and columns 2-4 and 6-8 reestimate these specifications in three variations while accounting for flush references. The (statistically weak) result that women in the uninformed condition in experiment 2 are more likely to obtain price concessions no longer holds in experiment 2 when accounting for flush reference, although the result does hold for experiment 1 when accounting for flush reference, as described previously.

Table A-10: Effects of information condition, robustness to inconsistent behavior

\begin{tabular}{|c|c|c|c|c|}
\hline Robustness Check & $\begin{array}{c}\text { (1) } \\
\text { Original Results }\end{array}$ & $\begin{array}{c}(2) \\
\% \text { Flush Reference }\end{array}$ & $\begin{array}{c}\text { (3) } \\
\text { Eliminate High Flush } \\
\text { Reference Agent-Weeks }\end{array}$ & $\begin{array}{c}(4) \\
\text { Eliminate High Flush } \\
\text { Reference Agents }\end{array}$ \\
\hline Dependent Variable & Price Quote & Price Quote & Price Quote & Price Quote \\
\hline Uninformed & $\begin{array}{l}2.5 \\
(4)\end{array}$ & $\begin{array}{c}3 \\
(4)\end{array}$ & $\begin{array}{c}3 \\
(4.2)\end{array}$ & $\begin{array}{c}5.4 \\
(4.5)\end{array}$ \\
\hline Misinformed & $\begin{array}{l}35^{* *} \\
(4.1)\end{array}$ & $\begin{array}{l}35^{* *}- \\
(4.1)\end{array}$ & $\begin{array}{l}33^{* *}- \\
(4.3)\end{array}$ & $\begin{array}{l}37^{* *^{-}} \\
(4.9)\end{array}$ \\
\hline$\%$ Flush Reference & & $\begin{array}{l}354^{*} x^{*--} \\
(102)\end{array}$ & & \\
\hline$\%$ Flush Reference Sq & & $\begin{array}{c}-1299^{* *-} \\
(445)\end{array}$ & & \\
\hline Second ${ }^{-}{ }^{-} \overline{l l}^{-}$ & $\begin{array}{l}13^{*-} \\
(5.4)\end{array}$ & $(5.4)$ & $\begin{array}{l}\overline{1} \overline{2}^{*^{--}} \\
(5.3)\end{array}$ & $\begin{array}{c}9.2 \\
(6.1)\end{array}$ \\
\hline $\begin{array}{l}\text { Week Fixed Effects } \\
\text { DMA Fixed Effects }\end{array}$ & $\sqrt{2}$ & $\checkmark$ & $\checkmark$ & $\checkmark$ \\
\hline Constant & $\begin{array}{l}388^{*} *-1 \\
(17)\end{array}$ & $\begin{array}{c}388^{* *-} \\
(17)\end{array}$ & $\begin{array}{c}387^{* *} \\
(17)\end{array}$ & $\begin{array}{c}382^{* *} \\
(17)\end{array}$ \\
\hline Observations & 4,603 & $4, \overline{0} 0 \overline{3}^{-}$ & 4,104 & 3,496 \\
\hline
\end{tabular}

* significant at $5 \%$;* significant at $1 \%$; significant at $10 \%$ level. Robust SEs in parentheses. 
Table A-11: Effects of information condition by gender, robustness to inconsistent behavior

\begin{tabular}{|c|c|c|c|c|}
\hline Robustness Check & $\begin{array}{c}\text { (1) } \\
\text { Original Results }\end{array}$ & $\begin{array}{c}(2) \\
\% \text { Flush Reference }\end{array}$ & $\begin{array}{c}\text { (3) } \\
\text { Eliminate High Flush } \\
\text { Reference Agent-Weeks }\end{array}$ & $\begin{array}{l}\text { (4) } \\
\text { Eliminate High Flush } \\
\text { Reference Agents }\end{array}$ \\
\hline Dependent Variable & Price Quote & Price Quote & Price Quote & Price Quote \\
\hline Informed, Women & $\begin{array}{l}-2.7 \\
(5.4)\end{array}$ & $\begin{array}{c}6.6 \\
(5.8)\end{array}$ & $\begin{array}{c}3.5 \\
(6.1)\end{array}$ & $\begin{array}{l}12+ \\
(6.8)\end{array}$ \\
\hline 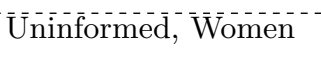 & $(5.5)$ & $\begin{array}{l}20^{* *}- \\
(5.9)\end{array}$ & $\begin{array}{l}(6) \\
16^{* *}-\end{array}$ & $\begin{array}{l}25^{* *^{-}} \\
(6.8)\end{array}$ \\
\hline Uninformèd, Men & $\begin{array}{l}-1 \overline{0}+ \\
(5.6)\end{array}$ & $\begin{array}{l}-7.9^{-} \\
(5.6)\end{array}$ & $\begin{array}{l}-9.4 \\
(6.3)\end{array}$ & $\begin{array}{l}-\overline{3} \cdot \overline{3} \\
(7.5)\end{array}$ \\
\hline Misinformed, Women & $(5.5)$ & $\begin{array}{l}43^{* *} \\
(5.9)\end{array}$ & $\begin{array}{c}38^{* *} \\
(6)\end{array}$ & $\begin{array}{l}{ }^{-1} \overline{6}^{\text {**- }} \\
(6.8)\end{array}$ \\
\hline Misinformed, Men & $(5.6)$ & $\begin{array}{l}33^{* *} \\
(5.5)\end{array}$ & $(6.4)$ & $(8.8)$ \\
\hline$\%$ F̂̀ush Reference & & $\begin{array}{l}51 \overline{9}^{*}{ }^{-} \\
(112)\end{array}$ & & \\
\hline 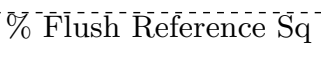 & & $\begin{array}{c}-182 \overline{9}^{* *^{-}} \\
(472)\end{array}$ & & \\
\hline Second ${ }^{-}$Call & $\begin{array}{l}1 \overline{1}^{*^{-}} \\
(5.4)\end{array}$ & $\begin{array}{l}11^{*^{-}-} \\
(5.4)\end{array}$ & $\begin{array}{c}8.8 \\
(5.4)\end{array}$ & $\begin{array}{l}7.4^{-} \\
(6.1)\end{array}$ \\
\hline $\begin{array}{l}\text { Week Fixed Effects } \\
\text { DMA Fixed Effects }\end{array}$ & $\checkmark$ & $\begin{array}{ll}-1 \\
\checkmark\end{array}$ & $\checkmark$ & $\checkmark$ \\
\hline Constant & $\begin{array}{c}388^{\text {** }} \\
(17)\end{array}$ & $\begin{array}{c}38 \overline{1}^{\text {** }}- \\
(17)\end{array}$ & $\begin{array}{c}38 \overline{8} \overline{2}^{\text {**- }} \\
(17)\end{array}$ & $\begin{array}{c}370^{* *} \\
(17)\end{array}$ \\
\hline Ōbservations & 4,603 & $\overline{4}, \overline{6} \overline{3}^{-}$ & 4,104 & 3,496 \\
\hline R-squared & 0.071 & 0.076 & 0.074 & 0.083 \\
\hline
\end{tabular}

significant at $5 \% ;{ }^{* *}$ significant at $1 \% ;+$ significant at $10 \%$ level. Robust SEs in parentheses. 


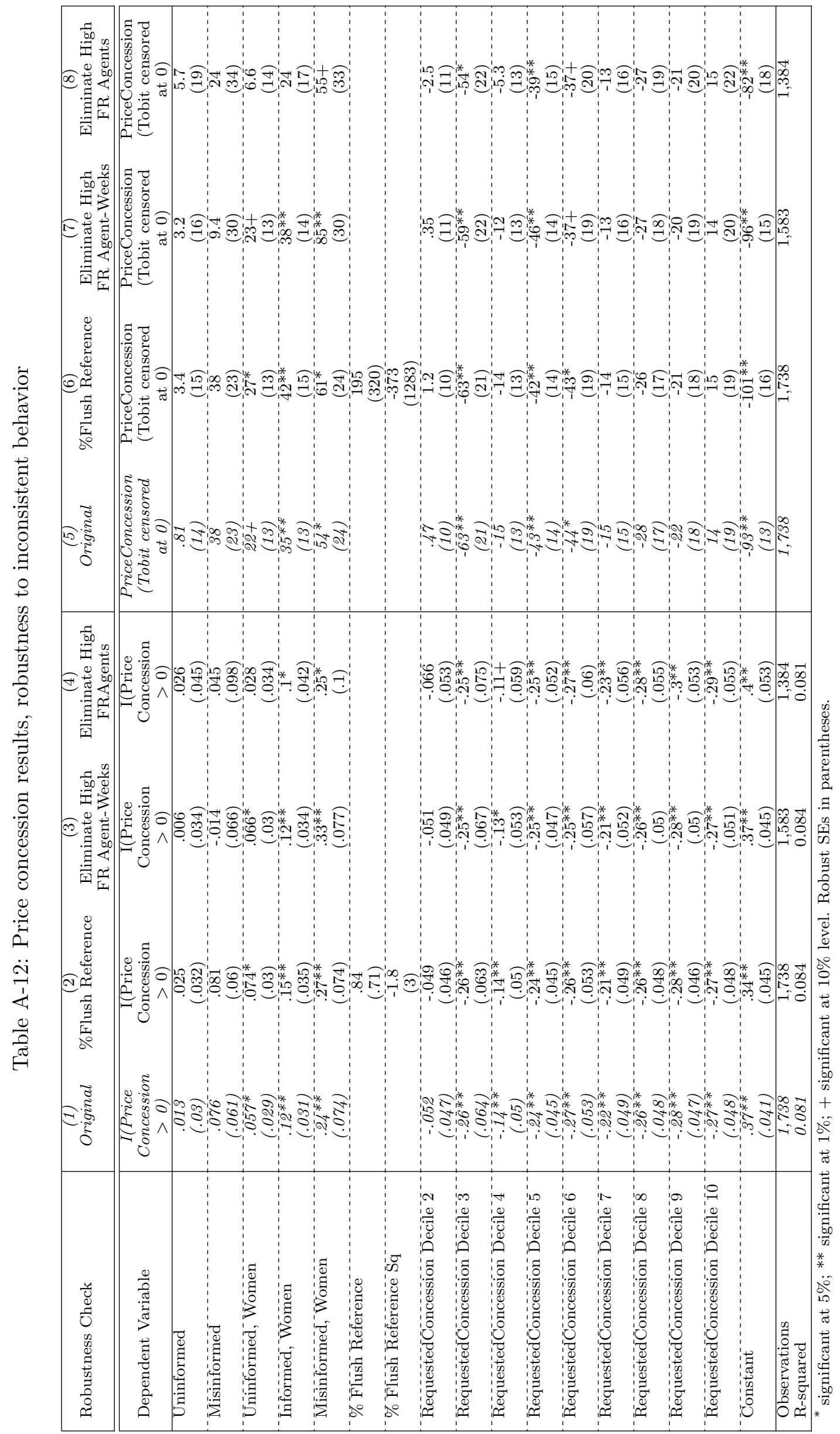

Web Appendix-17 
Table A-13: Experiment 2, initial price quote results, robustness to inconsistent behavior

\begin{tabular}{|c|c|c|c|c|}
\hline Robustness Check & $\begin{array}{c}(1) \\
\text { Original }\end{array}$ & \%Flush Reference & $\begin{array}{c}\text { (3) } \\
\text { Eliminate High } \\
\text { FR Agent-Weeks }\end{array}$ & $\begin{array}{c}\text { (4) } \\
\text { Eliminate High } \\
\text { FR Agents }\end{array}$ \\
\hline Dependent Variable & Price Quote & Price Quote & Price Quote & Price Quote \\
\hline Downward-Biased & $\begin{array}{c}-8.9 \\
(8)\end{array}$ & $\begin{array}{l}.72 \\
(8.8)\end{array}$ & $\begin{array}{l}1.4 \\
(9.9)\end{array}$ & $\begin{array}{l}-16 \\
(15)\end{array}$ \\
\hline Uninformed, Women & $\begin{array}{l}-5.7 \\
(6.9)\end{array}$ & $\begin{array}{l}1 \\
(9.4)\end{array}$ & $\begin{array}{l}8.6 \\
(8.9)\end{array}$ & $\begin{array}{l}-10 \\
(13)\end{array}$ \\
\hline Downward-Biased, Women & $\begin{array}{l}-5.2 \\
(6.9)\end{array}$ & $\begin{array}{l}1.5 \\
(7.5)\end{array}$ & $\begin{array}{l}.46 \\
(7.4)\end{array}$ & $(8.7)$ \\
\hline$\%$ Flush Reference & & $\begin{array}{l}-3 \overline{0} \overline{0}^{*-} \\
(143)\end{array}$ & & \\
\hline$\%$ Flush Reference Sq & & $\begin{array}{c}-690^{-} \\
(5466\end{array}$ & & \\
\hline${ }^{\prime} \overline{W e}^{-} \overline{1} \overline{3}^{-}$ & $(6.4)$ & $\begin{array}{l}-5 . \overline{4} \\
(6.5)\end{array}$ & $\begin{array}{l}-\overline{3} . \overline{9} \\
(6.6)\end{array}$ & $\begin{array}{l}-5.2 \\
(7.7)\end{array}$ \\
\hline Weè $\overline{1} 1 \overline{4}^{-}$ & $\begin{array}{l}-1.5 \\
(7.1)\end{array}$ & $\begin{array}{l}-7.7 \\
(7.3)\end{array}$ & $\begin{array}{l}-11 \\
(8)\end{array}$ & $\begin{array}{c}-12 \\
(8.6)\end{array}$ \\
\hline Weè $\overline{1} 5^{-}$ & $(8.6)$ & $\begin{array}{l}-11 \\
(8.8)\end{array}$ & $\begin{array}{l}-11^{-} \\
(9.2)\end{array}$ & $\begin{array}{l}-14 \\
(11)\end{array}$ \\
\hline $\bar{W}^{-} \overline{\mathrm{k}} \overline{1} \overline{6}^{-}$ & $\begin{array}{l}-\overline{2} \overline{2} \\
(14)\end{array}$ & $\begin{array}{l}-24 \overline{+} \\
(14)\end{array}$ & $\begin{array}{l}-23 \\
(14)\end{array}$ & $\begin{array}{l}-\overline{2} 2 \\
(14)\end{array}$ \\
\hline 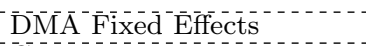 & 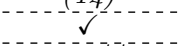 & -1 & -1 & -2 \\
\hline Constant & $\begin{array}{c}3 \overline{8} \overline{8}^{* *} \\
(14)\end{array}$ & $\begin{array}{c}375^{* *} \\
(15)\end{array}$ & $\begin{array}{c}378^{* *} \\
(15)\end{array}$ & $\begin{array}{c}40 \overline{8} * *- \\
(18)\end{array}$ \\
\hline $\begin{array}{l}\text { Observations } \\
\text { R-squared }\end{array}$ & $\begin{array}{l}1,941 \\
0.056\end{array}$ & $\begin{array}{l}1,941 \\
0.059\end{array}$ & $\begin{array}{l}1,651 \\
0.070\end{array}$ & $\begin{array}{l}1,513 \\
0.072\end{array}$ \\
\hline
\end{tabular}

${ }^{*}$ significant at $5 \% ;{ }^{* *}$ significant at $1 \% ;+$ significant at $10 \%$ level. Robust SEs in parentheses. 


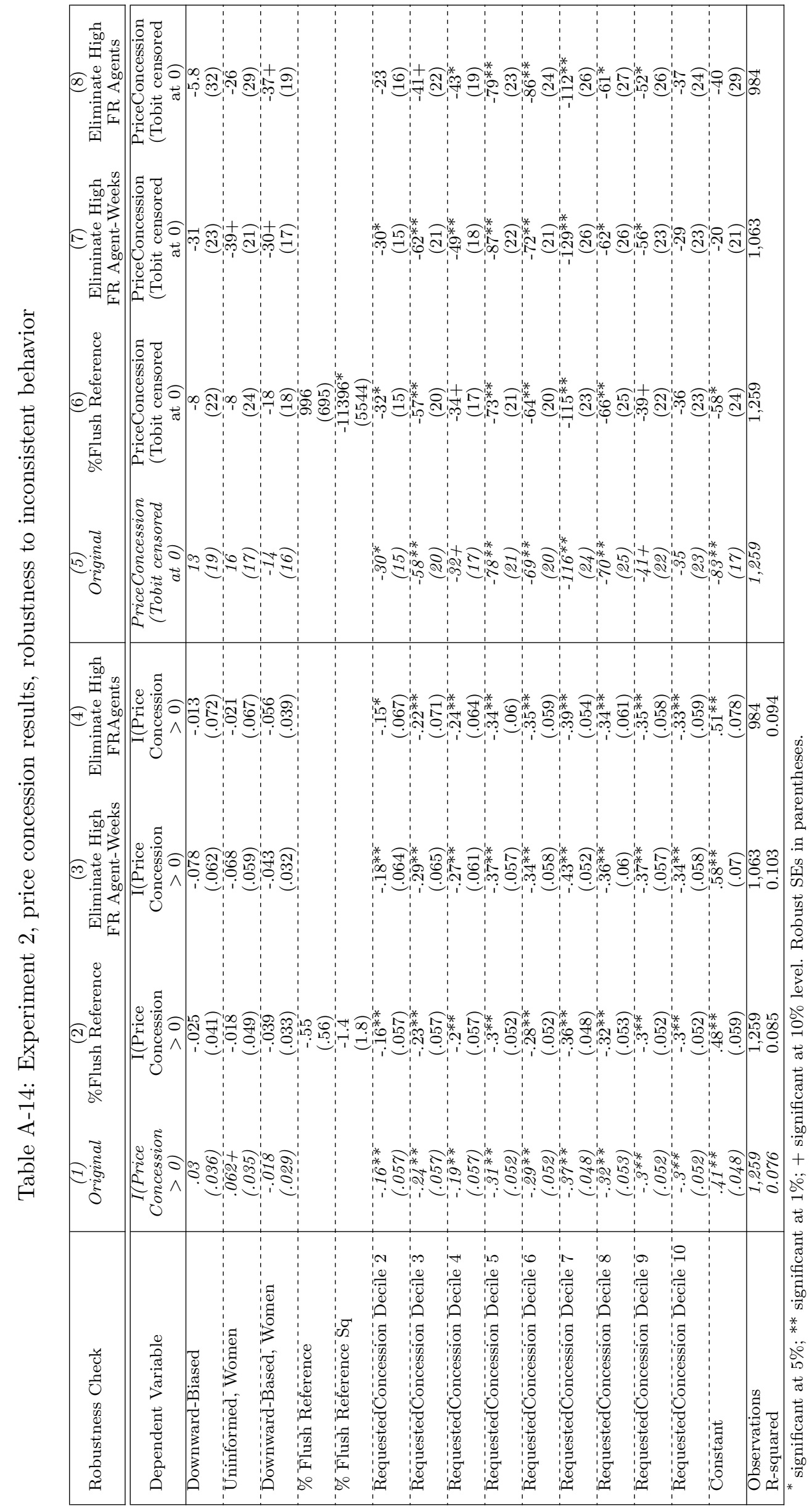

Web Appendix-19 